\title{
How many electrons holds a molecular
}

\section{electride?}

Sebastian P. Sitkiewicz, ${ }^{\dagger, \ddagger}$ Eloy Ramos-Cordoba, ${ }^{* \dagger, \dagger}$ Josep M. Luis, ${ }^{*, I I}$ and Eduard Matito*, $\uparrow, \S$

$\dagger$ Donostia International Physics Center (DIPC), 20018 Donostia, Euskadi, Spain $\ddagger$ Polimero eta Material Aurreratuak: Fisika, Kimika eta Teknologia, Kimika Fakultatea, Euskal

Herriko Unibertsitatea UPV/EHU, P.K. 1072, 20080 Donostia, Euskadi, Spain.

IInstitut de Química Computacional i Catàlisi (IQCC) and Departament de Química, Universitat

de Girona, 17003 Girona, Catalonia, Spain

§Ikerbasque Foundation for Science, Plaza Euskadi 5, 48009 Bilbao, Euskadi, Spain

E-mail: eloy.raco@gmail.com; josepm.luis@udg.edu; ematito@gmail.com

\begin{abstract}
Electrides are very peculiar ionic compounds where electrons occupy the anionic positions. In a crystal lattice, these isolated electrons often group forming channels or surfaces, furnishing electrides with a plethora of traits with promising technological applications. Despite their huge potential, thus far, only a few stable electrides have been produced because of the intricate synthesis they entail. Due to the difficulty in assessing the presence of isolated electrons, the characterization of electrides also poses some serious challenges. In fact, their properties are expected to depend on the arrangement of these electrons in the molecule. Among the criteria that we can use to characterize electrides, the presence of a non-nuclear attractor (NNA) of the electron density is both the rarest and the most salient feature. Therefore, a correct description of the NNA is crucial to determine the properties of electrides. In this paper, we analyze the
\end{abstract}


NNA and the surrounding region of nine molecular electrides with the goal of determining the number of isolated electrons that are held in the electride. We have seen that the correct description of a molecular electride hinges on the electronic structure method employed for the analyses. In particular, one should employ a basis set with sufficient flexibility to describe the region close to the NNA and a density functional approximation that does not suffer from large delocalization errors. Finally, we have classified these nine molecular electrides according to the most likely number of electrons that we can find in the NNA. We believe this classification highlights the strength of the electride character and will prove useful in the design of new electrides.

\section{Introduction}

Electrides are ionic species with electrons occupying the anionic positions. ${ }^{1-4}$ These anionic electrons in electrides act as separated individual entities, constituting the smallest possible anions in a molecule. All materials present defects at any temperature, due to misalignment or absence of atoms, the latter giving rise to vacancies that can be occupied by other particles. Farbe centers (from the German word Farben —color), commonly known as F centers, are vacancies occupied by electrons randomly displaced around the solid. The electrons in the vacancies can undergo energetic excitations (typically in the UV-Vis range) that give rise to colors in some mineral crystals such as gemstones. Electrides actually present stoichiometric F centers, i.e., the vacancies and isolated electrons are replicated in the crystal lattice. Electrides resemble alkaline metal solutions of ammonia, which form gold-blue colored materials that consist of positively charge alkaline metals and free electrons solvated by ammonia molecules. An important difference between electrides and solvated electrons is that the latter occur in the liquid disordered state, whereas the electrides have ordered geometrical structures.

James L. Dye, who had been working on the synthesis and characterization of compounds presenting anionic alkali metals — now commonly known as alkalides ${ }^{5}$ — was the first who hypothe- 
sized the existence of electrides. In 1983, he managed to synthesize the first electride ${ }^{6}$ and, finally, in 1986, he could unequivocally characterize it from the crystallographic structure. ${ }^{7}$ Afterwards, he also synthesized and characterized other electrides based on alkali metals, but unfortunately all of them eluded thermal stability or air sensitivity. 8,9 The electronic structure of these electrides hinges on the coordination of alkaline cations in a network structure and the formation of cavities (cages or channels) that can allocate the isolated electrons. For this reason, cryptand or crown ethers were chosen as complexants. However, all the organic electrides based on cryptand or crown ethers that had been synthesized thus far were not stable at room temperature and spontaneously decomposed at temperatures above $-40^{\circ} \mathrm{C}$. It actually took quite a long time to design the appropriate ligand (a cryptand[2.2.2]) to retain the cation that, in turn, would trap the electron in a close cavity. ${ }^{10}$ The synthesis of complexants that can bind alkali cations is tedious and complicated and, in this case, it required of previous computational calculations that guided the synthesis. Namely, electronic structure calculations suggested that decreasing the electronegativity of the coordination atom by replacing oxygen with nitrogen would raise the complexants' LUMO energies enough to make them inaccessible for the electron attachment that leads to the thermal decomposition of these complexants. ${ }^{10}$

Although Dye synthesized the first stable organic electride in 2005, the first stable electride was discovered by the group of Hideo Hosono two years earlier. ${ }^{11}\left[\mathrm{Ca}_{24} \mathrm{Al}_{28} \mathrm{O}_{64}\right]^{4+}\left(4 e^{-}\right)$is an inorganic electride that has found many applications: an electron emitter, ${ }^{12}$ an electron injection electrode for organic semiconductors, ${ }^{13}$ a synthetic organic reagent in pinacol coupling reaction, ${ }^{14} \mathrm{a}$ cathode in top-emission organic light-emitting diodes, ${ }^{15}$ a reversible $\mathrm{H}_{2}$ storage device, ${ }^{16}$ a catalyst in the synthesis of ammonia, ${ }^{17}$ an electrode in electrochemical reactions, ${ }^{18}$ fabrication of a fieldeffect transistor, ${ }^{19}$ as a cathode in a fluorescent lamp, ${ }^{20}$ and an electric conductor. ${ }^{21}$ The group of Hosono has been the most active in the search for new (inorganic) electrides with appealing applications, but other groups have recently joint the quest. Nowadays, there is a large collection of electrides, which can be classified in terms of the shape of the lattice voids where electrons are 
trapped: zero-dimensional electrides, ${ }^{22}$ one-dimensional electrides, ${ }^{23-26}$ two-dimensional electrides, ${ }^{27-34}$ three-dimensional ones, ${ }^{35-40}$ and electride nanoparticles. ${ }^{41,42}$ In Table 1 , we have collected all the experimental realizations of electrides, indicating which of them are stable at room temperature, whether they are organic or inorganic, and the number of dimensions of the isolated electron cavity. There are, however, other electrides that have been suggested in the literature based on computational calculations. ${ }^{43,44}$ This is the case of molecular electrides, ${ }^{45}$ which are single-molecule electrides, or metal cluster electrides, ${ }^{46}$ in which metal cations are surrounded by a sea of delocalized valence electrons.

Another route to avoid the use of chelating organic molecules to design electrides, consists in applying high pressures (hundreds of GPa) to alkaline metal structures. ${ }^{47}$ Upon compression of valence electrons, they separate one from another to minimize the electron repulsion. This way, there is a greater difficulty for electrons to move freely in the lattice and the material becomes a Mott insulator. This behavior has been observed in $\mathrm{Li},{ }^{48} \mathrm{Na},{ }^{49} \mathrm{~K},{ }^{47}$ and $\mathrm{Mg} .{ }^{50}$ These compounds were characterized by non-nuclear attractors (NNA) and maxima of the electron localization function (ELF) ${ }^{51}$, with a large number of electrons (between 1 and 2) in the corresponding basins. Hoffmann has worked on the chemical bonding formed between electrons of high-pressure electrides (called interstitial quasi-atoms (ISQs)) and their bonding capabilities, which can be traced back to those of atomic clusters in the so-called superatoms. ${ }^{52,53}$ An ISQ does not contain nuclei or core electrons, yet, due to its space confinement, an ISQ in a high-pressure electride acts as a regular atom, accommodating electrons and forming anions, giving rise to covalent and metallic bonds with the neighboring ISQs or atoms. Therefore, ISQs can form quasimolecules such as $\mathrm{E}_{2}$ bonds, $\mathrm{LiE}, \mathrm{MgE}_{2}$, and $\mathrm{EB}$, among others; $\mathrm{E}$ being the electron at the ISQ. 
Table 1: List of electrides synthesized up to 2021, including the type (organic/inorganic), its stability at room temperature with respect to air exposure (yes/no) and whether it is stable in the presence of water and acid, and the electron confinement regimen (zero-, one-, and two-dimensional, or nanoparticle).

\begin{tabular}{|c|c|c|c|c|}
\hline Electride & Type & Stable & Confinement & Ref \\
\hline $\mathrm{Cs}^{+}(18 \mathrm{C} 6)_{2} \cdot \mathrm{e}^{-}$ & Org. & not & $1 \mathrm{D}$ & 6 \\
\hline $\mathrm{K}^{+}(\mathrm{C} 222) \cdot \mathrm{e}^{-}$ & Org. & not & $2 \mathrm{D}$ & 54,55 \\
\hline $\mathrm{Cs}^{+}(15 \mathrm{C} 5)_{2} \cdot \mathrm{e}^{-}$ & Org. & not & $1 \mathrm{D}$ & 56 \\
\hline $\mathrm{Cs}^{+}[(15 \mathrm{C} 5)(18 \mathrm{C} 6)]_{6}(18 \mathrm{C} 6)$ & Org. & not & $2 \mathrm{D}$ & 57 \\
\hline $\mathrm{K}^{+}(15 \mathrm{C} 5)_{2} \cdot \mathrm{e}^{-}$ & Org. & not & $1 \mathrm{D}$ & 4 \\
\hline $\mathrm{Li}^{+}(\mathrm{C} 211) \cdot \mathrm{e}^{-}$ & Org. & not & $1 \mathrm{D}$ & 58 \\
\hline $\mathrm{Rb}^{+}(\mathrm{C} 222) \cdot \mathrm{e}^{-}$ & Org. & not & $1 \mathrm{D}$ & 59 \\
\hline $\mathrm{C} 12 \mathrm{~A} 7: \mathrm{e}^{-}$ & Inorg. & yes & OD & 11 \\
\hline $\mathrm{Na}^{+}\left[\right.$tri-pip-aza(222)] $\cdot \mathrm{e}^{-}$ & Org. & yes & $1 \mathrm{D}$ & 10 \\
\hline$\left[\mathrm{Ca}_{2} \mathrm{~N}\right]^{+} \cdot \mathrm{e}^{-}$ & Inorg. & yes & $2 \mathrm{D}$ & 27 \\
\hline$\left[\mathrm{Y}_{2} \mathrm{C}\right]^{1.8+} \cdot 1.8 \mathrm{e}^{-}$ & Inorg. & yes & $2 \mathrm{D}$ & 60 \\
\hline $\mathrm{La}_{8} \mathrm{Sr}_{2}\left(\mathrm{SiO}_{4}\right)_{6}^{4+} \cdot 4 \mathrm{e}^{-}$ & Inorg. & yes & $1 \mathrm{D}$ & 26 \\
\hline$\left[\mathrm{Y}_{5} \mathrm{Si}_{3}\right]^{0.79+} \cdot 0.79 \mathrm{e}^{-}$ & Inorg. & yes (water) & $1 \mathrm{D}$ & 61 \\
\hline $\mathrm{LnH}_{2}(\mathrm{Ln}=\mathrm{La}, \mathrm{Ce}, \mathrm{Y})$ & Inorg. & yes & OD & 22 \\
\hline exfoliated $\mathrm{Ca}_{2} \mathrm{~N}$ & Inorg. & yes & $2 \mathrm{D}$ & 33 \\
\hline $\mathrm{Nb}_{5} \mathrm{Ir}_{3}$ & Inorg. & yes & $1 \mathrm{D}$ & 24 \\
\hline $\mathrm{Sr}_{5} \mathrm{P}_{3}$ & Inorg. & yes & $1 \mathrm{D}$ & 25 \\
\hline $\operatorname{AeAlSi}(\mathrm{Ae}=\mathrm{Ca}, \mathrm{Sr}, \mathrm{Ba})$ & Inorg. & yes & $2 \mathrm{D}$ & 30 \\
\hline $\mathrm{LaScSi}$ & Inorg. & yes & $3 \mathrm{D}$ & 35 \\
\hline $\mathrm{LaCu}_{0.67} \mathrm{Si}_{1.33}$ & Inorg. & yes & $3 \mathrm{D}$ & 36 \\
\hline $\mathrm{Ru} / \mathrm{C} 12 \mathrm{~A} 7: \mathrm{e}^{-}$ & Inorg. & yes & OD & 62 \\
\hline $\mathrm{Yb}_{5} \mathrm{Sb}_{3}$ & Inorg. & yes & $2 \mathrm{D}$ & 29 \\
\hline $\mathrm{Ag}-\mathrm{Ca}_{2} \mathrm{~N}$ & Inorg. & yes & $2 \mathrm{D}$ & 63 \\
\hline $\mathrm{LaCu}_{0.67} \mathrm{Si}_{1.33}$ & Inorg. & yes & NP & 42 \\
\hline $\mathrm{Y}_{5} \mathrm{Si}_{3}$ & Inorg. & yes & NP & 42 \\
\hline $\mathrm{Sr}_{3} \mathrm{CrN}_{3}$ & Inorg. & N/A & $1 \mathrm{D}$ & 23 \\
\hline $\mathrm{Y}_{3} \mathrm{Pd}_{2}$ & Inorg. & yes & $3 \mathrm{D}$ & 40 \\
\hline LaRuSi & Inorg. & yes & $3 \mathrm{D}$ & 37 \\
\hline LnRuSi (Ln= La, Ce, Pr, Nd) & Inorg. & yes (water,acid) & $3 \mathrm{D}$ & 38 \\
\hline LnNiSi (Ln= La, Ce, Pr, Nd) & Inorg. & yes & $3 \mathrm{D}$ & 39 \\
\hline $\mathrm{Gd}_{2} \mathrm{C}$ & Inorg. & yes & $2 \mathrm{D}$ & 28 \\
\hline $\mathrm{Hf}_{2} \mathrm{~S}$ & Inorg. & yes (water, acid) & $2 \mathrm{D}$ & 32 \\
\hline$\left(\mathrm{Ca}_{1-x} \mathrm{Ba}_{x}\right) 12 \mathrm{~A} 7: \mathrm{e}^{-}(0 \leq \mathrm{x} \leq 0.05)$ & Inorg. & yes & OD & 64 \\
\hline $\mathrm{Sn} / \mathrm{C} 12 \mathrm{~A} 7: \mathrm{e}^{-}$ & Inorg. & yes & NP & 41 \\
\hline$\left(\mathrm{C}_{1-x} \mathrm{~S}_{x}\right) 12 \mathrm{~A} 7: \mathrm{e}^{-}(0 \leq \mathrm{x} \leq 0.03)$ & Inorg. & yes & $0 \mathrm{D}$ & 65 \\
\hline
\end{tabular}


The characterization of electrides is not free of ambiguity. ${ }^{45,46,66}$ Nevertheless, electrides present a number of special properties that could be used to identify them. For instance, solid-state electrides show particular magnetic features that result from the presence of unpaired spins such as exalted susceptibilities that correlate with the area of channel where the isolated electrons are located. An electride is expected to be a Mott insulator and some electrides are superconductors at low temperatures. ${ }^{13,67-69}$ In addition, they also present huge non-linear optical properties (NLOPs), which include some of the largest static first hyperpolarizabilities ever reported..$^{70,71}$ However, none of these properties are exclusive of electrides, and one is deemed to measure the most salient feature of electrides: the existence of an isolated electron. Hence, the characterization of electrides depends on the ability of experimental and computational techniques to unequivocally identify the presence of isolated electrons. Since the density of free electrons is not large enough to be located in the X-ray of the crystal structure, most experimental evidences of the presence of this electron are indirect ${ }^{8,9,72}$ and come usually from: $(i)$ the similarity of the electride structure with analogue alkalides (i.e., the cationic structure), (ii) the chemical shift of the corresponding cation, (iii) EPR studies, and (iv) atomic-resolution scanning tunneling microscopy. ${ }^{73}$ The theoretical analysis often provides more reliable ways to characterize electrides, through the characterization of the topology of the electron density, the ELF, ${ }^{51,74,75}$ the noncovalent interactions (NCI), ${ }^{76,77}$ the localized-orbital locator (LOL), ${ }^{78}$ and the Laplacian of the electron density. ${ }^{79}$ These tools are useful to identify localized electrons in electrides $45,46,66,80$ but these features are also separately present in many systems that cannot be considered electrides. In 2015, some of us established the following computational criteria to identify molecular electrides: the presence of a NNA, a highly localized density (indicated by the ELF, the Laplacian of the electron density or another indicator such as LOL) and large nonlinear optical properties. ${ }^{45}$ Dale et al. have recently also reviewed these and other criteria to recognize electrides. ${ }^{66}$ They confirm that our criteria are adequate to identify molecular electrides, however, they found some difficulties to detect NNAs in inorganic electrides because of the compact nature of their vacancies. ${ }^{66}$ One should also keep in mind that many density functional approximations (DFAs) suffer from delocalization errors that 
are caused by spurious self-interactions (known as the self-interaction error) that result in the overestimation of the electron delocalization in the molecule. ${ }^{81}$ As a result, DFAs with a low percentage of Hartree-Fock (HF) exchange tend to overestimate electron conjugation ${ }^{82}$ and aromaticity. ${ }^{83-86}$ In the case of electrides, the delocalization error might hinder the presence of NNAs in electronic densities of solid-state inorganic electrides (vide infra). ${ }^{80}$

Among the criteria that can be used to identify electrides, the NNA is the rarest feature and, therefore, it is assumed that the existence of a NNA indicates that, most likely, the molecule is an electride. It is thus important to find the adequate electronic structure method to detect the NNA which, as we shall see, is quite sensitive to both the accuracy of the method and the quality of the basis set employed. The correct characterization of the electron density around the NNA is necessary to assess the properties of the NNA basin (delimited by the density zero-flux surface surrounding the NNA), which, in turn, will determine the properties of the electride. In this sense, some questions about electrides remain unanswered. Which is the most likely number of electrons that holds an electride? Can we connect the latter with the formal oxidation state of the NNA basin? Which is the probability of finding at least one electron in the NNA basin? To which extent are the isolated electrons in an electride localized? In this paper, we will address these queries and show that there are a few types of electrides according to the number of electrons the NNA basin holds. We will also assess the sensitivity of the computational method employed to characterize molecular electrides. We believe this study, apart from providing insight on the formal characterization of the electrides, will also help to understand the electronic structure arrangement in molecular electrides and, therefore, help into the design of new electrides. 


\section{Methodology}

In this paper, we have studied several molecules (see Figure 1 for the molecular representation of the systems) that were already classified as molecular electrides following the criteria we established:"45 Li@calix[4]pyrrole, ${ }^{45,70,87} \mathrm{Na@calix[4]pyrrole,}{ }^{88} \mathrm{TCNQLi}_{2},{ }^{45,89} \mathrm{TCNQNa}_{2},{ }^{45,89}$ $\mathrm{TCNENa}_{3},{ }^{90} \mathrm{TCNENa}_{4}(\mathrm{II}),{ }^{90} \mathrm{Mg}_{2} \mathrm{EP},{ }^{91} \mathrm{Mg}_{2} @ \mathrm{C}_{60},{ }^{88}$, and e $@ \mathrm{C}_{60} \mathrm{~F}_{60} \cdot{ }^{45,92}$ Namely, all of these systems present at least a NNA, a highly localized density in the region of the NNA —indicated by the large negative value of the Laplacian of the electron density ${ }^{79}$ or the presence of an ELF ${ }^{51,74}$ basin - and large nonlinear optical properties (NLOPs). For TCNENa 3 and TCNENa $(\mathrm{II})$, only the values of the static first hyperpolarizability were reported. ${ }^{90}$ For the sake of completeness, in the Supporting Information, we have included the static NLOPs (up to the second hyperpolarizability) of these molecules, which are of the same magnitude as in other molecular electrides.

All structures were optimized at the CAM-B3LYP/ma-TZVP ${ }^{93,94}$ level of theory. It has been recently documented that this functional avoids large delocalization errors, ${ }^{83-85}$ which could give rise to spurious critical points in the potential energy surface. ${ }^{86,95}$ For these optimized geometries, single-point calculations with various basis sets and density functional approximations (CAMB3LYP, ${ }^{93}$ B3LYP, ${ }^{96,97}$ M06-2X, ${ }^{98}$ and MN15 ${ }^{99}$ ) as well as Hartree-Fock (HF) and MP2 ${ }^{100}$ methods have been performed. Although HF completely neglects electron correlation and, in most cases, density functional approximations (DFAs) provide more accurate energies and geometries, DFAs struggle to reproduce the electron density of some electrides with unpaired electrons. Conversely, HF densities are usually of sufficient quality (at least they do not suffer from delocalization errors) to provide a correct description of the system. This way, we have an alternative method which, in some cases, provides results closer to correlated ab initio methods (see Results section). The purpose of performing such benchmarking calculations is to assess the accuracy of each DFA and measure the effect of the delocalization error in the characterization of the isolated electron(s). For TCNENa 3 , additional calculations with CCSD and CCSD(T) were also included to assess the performance of MP2, which is the reference for all the other systems. In order to confirm the single-reference nature of $\mathrm{TCNENa}_{3}$, we performed T1, ${ }^{101}$ and D1 diagnostics ${ }^{102}$ on 

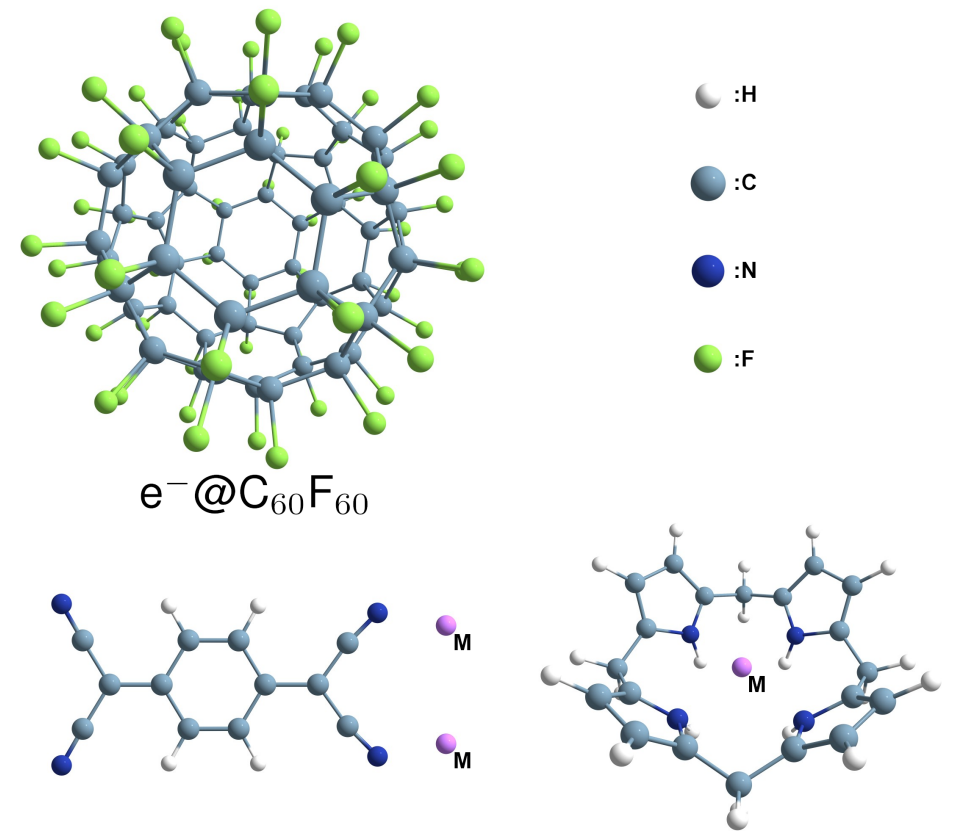

$\mathrm{TCNQM}_{2}$

M@calix[4]pyrrole

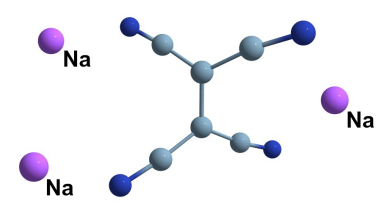

$\mathrm{TCNENa}_{3}$
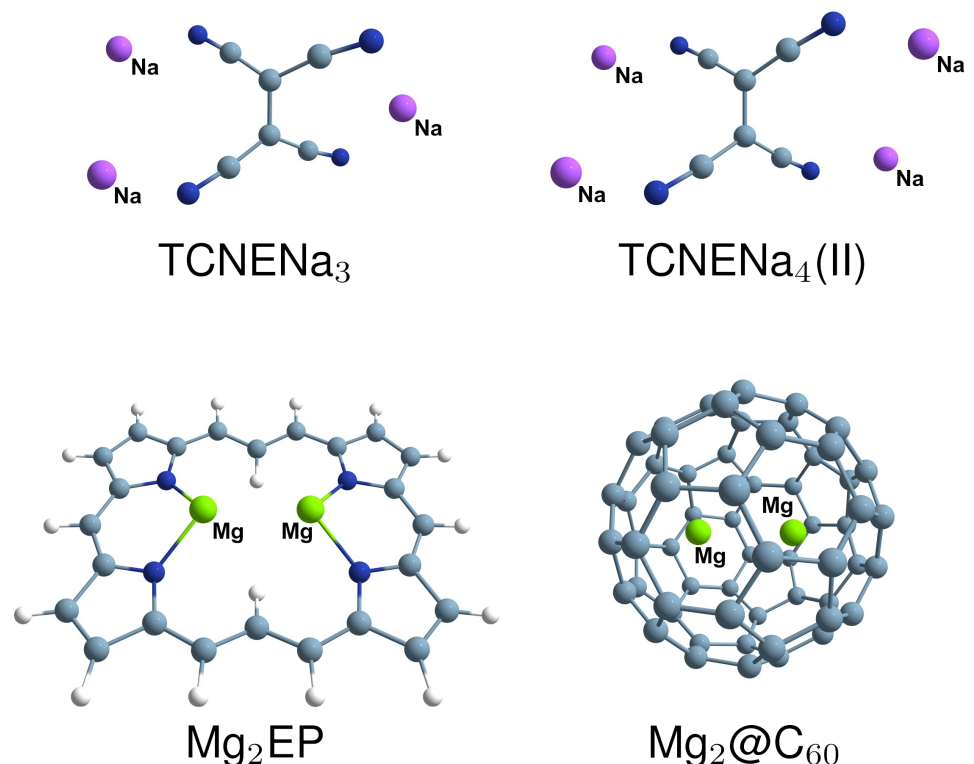

$\mathrm{Mg}_{2} @ \mathrm{C}_{60}$

Figure 1: Molecular representations of Li@calix[4]pyrrole, ${ }^{45,70,87} \mathrm{Na@calix[4]pyrrole,}{ }^{88}$ $\mathrm{TCNQLi}_{2},{ }^{45,89} \mathrm{TCNQNa}_{2},{ }^{45,89} \mathrm{TCNENa}_{3},{ }^{90} \mathrm{TCNENa}_{4}(\mathrm{II}),{ }^{90} \mathrm{Mg}_{2} \mathrm{EP},{ }^{91} \mathrm{Mg}_{2} @ \mathrm{C}_{60},{ }^{88}$ and e@ $\mathrm{C}_{60} \mathrm{~F}_{60}{ }^{45,92}$ optimized at the CAM-B3LYP/ma-TZVP level of theory. Molecules with an $M$ atom have been optimized and studied for $M=\mathrm{Li}$ and $M=\mathrm{Na}$. 
the coupled-cluster wavefunction. For all CCSD and MP2 wavefunctions, we have computed the $I_{N D}$ index ${ }^{103,104}$ obtained from the range-separation partition of the Coulomb hole. ${ }^{105,106} I_{N D}$ is proportional to the deviation from idempotency of the first-order reduced density matrix. ${ }^{107,108}$ Unlike T1 and D1 diagnostics, $I_{N D}$ can be calculated for any wavefunction from natural orbital occupations. All HF, MP2, and DFAs calculations were performed with Gaussian16 (Rev. B01) ${ }^{109}$ whereas CCSD and CCSD(T) calculations were computed using CFOUR 2.1. ${ }^{110}$ For all post-HF methods, relaxed densities have been employed in the subsequent analyses (vide infra).

The study of the electronic distribution in electrides was done in the framework of the quantum theory of atoms in molecules (QTAIM) ${ }^{79}$ using the AIMAll package (ver. 19.10.12). ${ }^{111}$ This software was used to perform a topological analysis of the electron density, detect the presence of non-nuclear attractors (NNAs) ${ }^{112}$ and integrate the number of electrons in the corresponding NNA basins (NNA population). We also calculate the localization index, ${ }^{113,114}$ which gives a measure of the number of electrons localized in this region. In addition, we performed an effective oxidation state (EOS) analysis ${ }^{115,116}$ to assign an integer number of electrons to the NNA basin. Unlike the NNA population, which gives the average number of electrons in the NNA basin, the NNA EOS is an integer number (or, occasionally, a rational number) that is expected to provide a value close to the formal ionic picture ${ }^{116}$ of the NNA basin. The two values provide important complementary information about the electronic structure of a molecule.

In order to perform the EOS analysis, we always define one fragment for each NNA basin we have identified in the molecule. The rest of the molecule will be divided into two different ways: (1) considering one whole fragment or (2) separating metallic centers from the rest of the molecule. The EOS method defines a set of effective atomic orbitals (EffAOs) and occupations from the atomic overlap matrix obtained from the QTAIM analysis. The EffAOs are ranked in decreasing occupation order and, one by one, the electrons of the molecule are assigned to the different fragments. The procedure is done separately for alpha and beta electrons. The number of electrons assigned to each fragment determines its oxidation state, while the occupations of the 
EffAOs are also used to calculate a measure of the uncertainty of the oxidation state assignment (vide infra). The EOS analysis has been recently used to assign oxidation states in a number of nontrivial molecules. ${ }^{95,117-121}$ In this work, we have employed APOST3D (dev. ver. 2.0) to perform the EOS study. ${ }^{122}$ Finally, we have calculated the electron distribution functions (EDFs) ${ }^{123}$ to analyze the probability of finding zero, one, and two electrons in the NNA. To this end, we have implemented the formulation of Cancés et al. ${ }^{124}$ in an in-house version of APOST3D.

\section{Results}

In this section, we will present the results gathered for the nine molecular electrides we have selected for our study. First of all, we will choose the most adequate computational method to analyze these systems by examining several density functional approximations (DFAs) and $a b$ initio methods. Afterwards, we will determine the most likely number of electrons that contribute to the electride character of each molecule and determine the oxidation state of the region that contains the isolated electrons of the studied electrides. Finally, we will compare the different descriptors used to characterize the electrides and determine which ones can be used to assess the number of electrons in electrides.

\section{Calibration of the computational method}

In this work, we will employ MP2 as the reference method to compare the features obtained from the topological analysis of the electron density, including the density and its Laplacian at the NNA, the average number of electrons in the NNA $\left(N_{\mathrm{NNA}}\right)$, and the number of electrons localized in the NNA $\left(\lambda_{\text {NNA }}\right)$ or localization index. ${ }^{113,114}$ In order to assess the accuracy of MP2, we have selected $\mathrm{TCNENa}_{3}$, for which MP2 presented a large deviation with respect to all the DFAs tested (see

$N_{\mathrm{NNA}}$ and $\lambda_{\mathrm{NNA}}$ in Table 9), and performed additional CCSD and CCSD(T) calculations. For the sake of convenience, for this particular test, we have selected a smaller basis set, cc-pVTZ, which does not include diffuse functions. Fortunately, for this system, diffuse functions are not needed to 
obtain accurate descriptors related to the electron density (compare the cc-pVTZ and aug-cc-pVTZ results of Tables 2 and 9).

Results of the QTAIM analysis at different levels of theory are displayed in Table 2. MP2 gives essentially the same topology of the density as CCSD and $\operatorname{CCSD}(\mathrm{T})$, including the value of the density and its Laplacian at the position of the NNA. The average number and the localized electrons in the NNA basin are very similar for MP2, CCSD, and CCSD(T) wavefunctions, and slightly overestimated using a HF wavefunction. In order to assess the single-reference character of this system, we performed T1 and D1 diagnostics, which confirmed the lack of multireference character in this system (see Table 3). Further confirmation is obtained from the largest single and double excitation amplitudes in CCSD, which are of order of 0.02. Finally, in Table 4, we collect $I_{N D}$ for all the MP2 wavefunctions, which is below 0.037 in all cases, indicating a low multireference character for the molecules studied in this paper (as a reference, $I_{N D}=0.50$ for the dissociated $\mathrm{H}_{2}$ molecule, whereas $I_{N D}=0.038$ would correspond to the $\mathrm{H}_{2}$ molecule at $R_{H H}=$ $0.86 \AA, R_{H H}=0.74 \AA$ being the equilibrium geometry). These results confirm that MP2 is a good reference system to study the electronic distribution in these molecular electrides.

Table 2: Results of the QTAIM partitioning for $\mathrm{TCNENa}_{3}$ at various levels of theory with the cc-pVTZ basis set. For the description of columns, see Table 5.

\begin{tabular}{ccccc} 
Method & $\rho\left(\mathbf{r}_{\mathrm{NNA}}\right)$ & $\nabla^{2} \rho\left(\mathbf{r}_{\mathrm{NNA}}\right)$ & $N_{\mathrm{NNA}}$ & $\lambda_{\mathrm{NNA}}$ \\
\hline \hline HF & $7.2 \mathrm{E}-03$ & $-5.4 \mathrm{E}-03$ & 0.487 & 0.231 \\
MP2 & $7.1 \mathrm{E}-03$ & $-5.3 \mathrm{E}-03$ & 0.459 & 0.206 \\
CCSD & $7.1 \mathrm{E}-03$ & $-5.3 \mathrm{E}-03$ & 0.459 & 0.207 \\
$\mathrm{CCSD}(\mathrm{T})$ & $7.1 \mathrm{E}-03$ & $-5.2 \mathrm{E}-03$ & 0.453 & 0.202
\end{tabular}

Table 3: Multireference diagnostics of the $\mathrm{TCNENa}_{3}$ CCSD wavefunction with different basis sets. All the calculations display values below the recommended thresholds $\left(\mathrm{T}_{1}^{\mathrm{MR}} \geq 0.02\right.$ and $\left.\mathrm{D}_{1}^{\mathrm{MR}} \geq 0.05\right){ }^{101,102}$

\begin{tabular}{cccc} 
Basis set & $\mathrm{T}_{1}$ & $\mathrm{D}_{1}$ & $I_{N D}$ \\
\hline cc-pVTZ & 0.0164 & 0.0446 & 0.022 \\
def2-TZVP & 0.0164 & 0.0448 & 0.022
\end{tabular}


Table 4: Values of the nondynamical correlation index $\left(I_{N D}\right)^{103,104}$ calculated using occupancies of natural orbitals obtained with MP2 and various basis sets.

\begin{tabular}{ccc} 
Molecule & Basis set & $I_{N D}$ \\
\hline \hline \multirow{2}{*}{ TCNQLi $_{2}$} & aug-cc-pVTZ & 0.021 \\
& ma-TZVP & 0.021 \\
\hline \multirow{2}{*}{ TCNQNa $_{2}$} & aug-cc-pVTZ & 0.019 \\
& ma-TZVP & 0.018 \\
\hline \multirow{2}{*}{ Li@calix[4]pyrrole } & aug-cc-pVTZ & 0.030 \\
& ma-TZVP & 0.029 \\
\hline \multirow{2}{*}{ Na@calix[4]pyrrole } & aug-cc-pVTZ & 0.029 \\
& ma-TZVP & 0.028 \\
\hline \multirow{2}{*}{ TCNENa $_{3}$} & aug-cc-pVTZ & 0.023 \\
& ma-TZVP & 0.023 \\
\hline \multirow{2}{*}{$\mathrm{TCNENa}_{4}(\mathrm{II})$} & aug-cc-pVTZ & 0.020 \\
& ma-TZVP & 0.020 \\
\hline \multirow{2}{*}{$\mathrm{Mg}_{2} \mathrm{EP}^{2}$} & aug-cc-pVTZ & 0.031 \\
\multirow{2}{*}{$\mathrm{Mg}_{2} @ \mathrm{C}_{60}$} & ma-TZVP & 0.031 \\
\hline \multirow{2}{*}{ aug-cc-pVTZ } & 0.036 \\
& ma-TZVP & 0.036 \\
\hline $\mathrm{C}_{60} \mathrm{~F}_{60}$ & 6-31G(d)+DF & 0.021 \\
& 6-31+G+DF & 0.017 \\
& 6-31G+DF & 0.017 \\
& cc-pVDZ+DF & 0.021 \\
\hline
\end{tabular}

\section{Which is the most likely number of electrons in molecular electrides?}

In order to determine the number of electrons that are contained in the NNA basin (hereafter, electron numbers), we will analyze several properties related to the NNA. First, we will collect some topological indicators such as the electron density at the non-nuclear attractor, $\rho\left(\mathbf{r}_{\mathrm{NNA}}\right)$, and the local charge concentration at this point, measured through the Laplacian of the electron density, $\nabla^{2} \rho\left(\mathbf{r}_{\mathrm{NNA}}\right)$. We expect these quantities to increase and decrease, respectively, with the electron numbers. We will also measure the average number of electrons that we can find in the NNA basin, $N_{\mathrm{NNA}}$ and the number of localized electrons in this basin, $\lambda_{\mathrm{NNA}}$. The latter quantity is directly connected with the uncertainty in the electron population of the NNA basin, $\delta_{\mathrm{NNA}}$, where $N_{\mathrm{NNA}}=\lambda_{\mathrm{NNA}}+\delta_{\mathrm{NNA}} \cdot 114,125,126$ 
We will also compute the probability of having exactly zero, one and two electrons inside the NNA basin for single-determinant wavefunctions (in the case of DFAs, we will employ the KohnSham wavefunction), which, following the work of Cancés et al., ${ }^{124}$ can be calculated as follows,

$$
P_{0}^{A}=\prod_{i=1}^{N}\left(1-\lambda_{i}^{A}\right)
$$

and, if $P_{0}^{A} \neq 0$, the probability of finding exactly $n$ electrons in the region $A, P_{n}^{A}$, is given by

$$
P_{n}^{A}=\sum_{i_{1}, \ldots, i_{n}}^{N} \prod_{j=1}^{n}\left(\frac{\lambda_{i_{j}}^{A}}{1-\lambda_{i_{j}}^{A}}\right) P_{0}^{A} \quad \forall n>0
$$

where the prime in the summation indicates that we are excluding terms with repeated indices, and $\lambda_{i}^{A}$ are the $N$ eigenvalues of the atomic overlap matrix for the basin $A$. Hereafter, we will only consider the basin of the NNA and thus we will drop the notation indicating the region $\left(P_{i} \equiv P_{i}^{\mathrm{NAA}}\right.$ and $\lambda_{i} \equiv \lambda_{i}^{\mathrm{NNA}}$ ). These probabilities, which are now generically known as electron distribution functions (EDFs), were introduced in chemistry by Daudel ${ }^{127,128}$ and have been extensively used by Martín Pendás and co-workers, ${ }^{123,129,130}$ as an elegant tool to characterize chemical bonds. ${ }^{131}$ One can easily retrieve the average number of electrons in the NNA basin using the EDFs:

$$
N_{\mathrm{NNA}}=\sum_{i} i P_{i}
$$

In the present case, the probability of finding more than two electrons in the NNA basin is expected to be negligible, hence, $N_{\mathrm{NNA}} \approx P_{1}+2 P_{2}$. We will consider that the molecule is at least a one-electron molecular electride if the probability of having at least one electron, $1-P_{0}$, is higher than the opposite, $P_{0}$.

Finally, we will employ the effective oxidation state (EOS) tool developed by Salvador and co-workers. ${ }^{115,116}$ Namely, we will calculate the EOS of the NNA basin, which will provide the 
oxidation state of the NNA basin. In order to calculate the EOS, we must define real-space fragments among which the electrons will be distributed. We will test two partitions: EOS[1], which will consider only two fragments: the NNA basin and the rest of molecule, and EOS[2], which will divide the space into several fragments: the NNA basins, one fragment for each metallic atom, and the rest of the molecule. The only exception is the $e @ \mathrm{C}_{60} \mathrm{~F}_{60}$ system, in which only type 1 fragmentation can be applied because there are no metallic centers. The reliability index (RI) is a measure that accompanies the EOS analysis, giving the likelihood of a correct prediction of the oxidation state. The RI is calculated using the following expression:

$$
\mathrm{RI}(\%)=100 \min \left(R_{\alpha}, R_{\beta}\right)
$$

where

$$
R_{\sigma}=\min \left(1, \Delta \lambda^{\sigma}+1 / 2\right)
$$

and $\Delta \lambda^{\sigma}=\lambda_{\mathrm{LO}}^{\sigma}-\lambda_{\mathrm{FU}}^{\sigma}$, LO and FU staying for lowest-occupied and first-unoccupied EffAOs, respectively. RI will take values between 50\% (highest uncertainty) and 100\% (lowest uncertainty). The EOS will be compared against the highest $P_{i}$ value obtained from the EDFs.

\section{TCNQLi 2}

The ground state of TCNQLi $2\left({ }^{3} B_{1}\right)$ was characterized using different methods and various basis sets (see Table 5). In all cases, except for B3LYP/ma-TZVP, CAM-B3LYP/ma-TZVP, and M06-2X/ma-TZVP densities, a single non-nuclear attractor was located between the Li atoms (see Figure 2). B3LYP/ma-TZVP and CAM-B3LYP/ma-TZVP electronic densities do not display a NNA whereas, in the case of M06-2X/ma-TZVP, two close NNAs are located between Li atoms. Except for the calculations performed with the ma-TZVP basis set, ${ }^{94}$ the values of the density and its Laplacian at the NNA are very similar for all the methods and basis sets studied. A careful inspection of this basis set reveals that ma-TZVP does not present functions of angular momentum higher than 1 for Li, whereas ma-QZVP, cc-pVTZ, and aug-cc-pVTZ present $d$ and $f$ functions, 
and some extra $p$ functions with lower exponents. Since we are employing atom-centered basis sets, the presence of the latter functions on $\mathrm{Li}$ are essential for a correct description of the electron density in the NNA region. For this reason, we will not consider the results obtained with ma-TZVP basis set for this molecule.

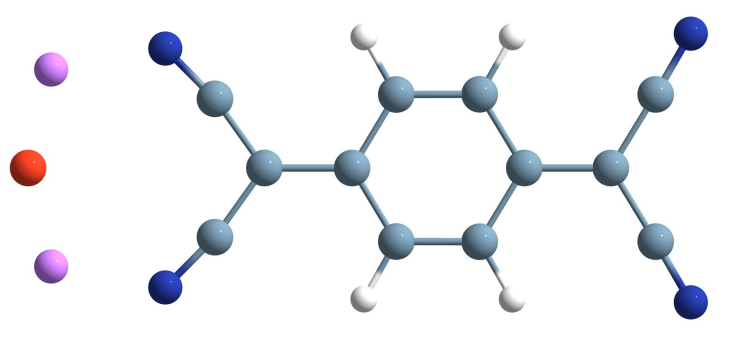

Figure 2: Geometry of TCNQLi 2 optimized at the CAM-B3LYP/ma-TZVP level of theory. A single-point calculation with aug-cc-pVTZ basis set was used to retrieve the position of the NNA, which is indicated with a red ball.

The population and the number of electrons localized at the NNA basin increase with the percentage of HF exchange employed in the method (B3LYP, 19\%, CAM-B3LYP, 19-65\%, M06-2X, 54\%, HF and MP2, 100\%), HF providing the closest agreement with MP2 data. The population of the NNA oscillates between 0.5 and 0.7 electrons, in agreement with the oxidation state of -1 assigned by the EOS analysis. This oxidation state is predicted with a RI that increases with the average number of electrons and the number of electrons localized in the NNA (compare different methods in Table 5). Interestingly, the RI increases if the electrons are distributed among more fragments. Namely, the RI is larger for EOS[2], which distributes the electrons in the electrides among the NNA, the two Li atoms and the rest of molecule. As we shall see, it is not the most common situation; more fragmentation usually increases the uncertainty of the EOS assignment and, in general, EOS[1] will be equal or higher than EOS[2]. A simple inspection of the probability distributions in the NNA basin, reveals that the highest probability always corresponds to the oxidation state predicted by the EOS analysis. Furthermore, there is a good correspondence between the value of the probability and the RI value predicted by the first fragmentation (EOS[1]). In this 
case, the two most likely events are those in which the NNA basin holds zero and one electron, the latter being clearly the preferred situation for most methods. Hence, according to EOS and EDF criteria, we can classify $\mathrm{TCNQLi}_{2}$ as a one-electron molecular electride. 
Table 5: Results of the QTAIM partitioning for TCNQLi 2 . The third and fourth columns report values of the density, $\rho\left(\mathbf{r}_{\mathrm{NNA}}\right)$, and its Laplacian, $\nabla^{2} \rho\left(\mathbf{r}_{\mathrm{NNA}}\right)$, at the positions of the NNA. The fifth and sixth columns give the population, $N_{\mathrm{NNA}}$, and localization index, $\lambda_{\mathrm{NNA}}$, for the NNA basin. Starting on the seventh column, results of the EOS and EDF analyses of the NNA basin are given. EOS[1] and EOS[2] correspond to the oxidation state obtained with type 1 and 2 fragmentations, respectively (see text). The last three columns report the probabilities (in percentage) of finding 0, 1, and 2 electrons in the NNA basin.

\begin{tabular}{|c|c|c|c|c|c|c|c|c|c|c|c|c|}
\hline Method & Basis & $\rho\left(\mathbf{r}_{\mathrm{NNA}}\right)$ & $\nabla^{2} \rho\left(\mathbf{r}_{\mathrm{NNA}}\right)$ & $N_{\mathrm{NNA}}$ & $\lambda_{\mathrm{NNA}}$ & EOS[1] & RI & EOS[2] & RI & $\mathrm{P}_{0}$ & $\mathrm{P}_{1}$ & $\mathrm{P}_{2}$ \\
\hline \multirow{4}{*}{ CAM-B3LYP } & ma-TZVP & \multicolumn{11}{|c|}{ no NNAs } \\
\hline & ma-QZVP & $9.6 \mathrm{E}-03$ & $-8.2 \mathrm{E}-03$ & 0.540 & 0.277 & -1 & 55 & -1 & 83 & 46.9 & 52.6 & 0.6 \\
\hline & cc-pVTZ & $9.6 \mathrm{E}-03$ & $-8.3 \mathrm{E}-03$ & 0.563 & 0.300 & -1 & 60 & -1 & 87 & 44.7 & 54.7 & 0.6 \\
\hline & aug-cc-pVTZ & $9.6 \mathrm{E}-03$ & $-8.3 \mathrm{E}-03$ & 0.557 & 0.295 & -1 & 59 & -1 & 86 & 45.2 & 54.2 & 0.6 \\
\hline \multirow{4}{*}{ B3LYP } & ma-TZVP & \multicolumn{11}{|c|}{ no NNAs } \\
\hline & ma-QZVP & $9.4 \mathrm{E}-03$ & $-7.9 \mathrm{E}-03$ & 0.505 & 0.242 & 0 & 52 & -1 & 79 & 50.3 & 49.2 & 0.5 \\
\hline & cc-pVTZ & $9.4 \mathrm{E}-03$ & $-8.1 \mathrm{E}-03$ & 0.527 & 0.262 & -1 & 52 & -1 & 82 & 48.3 & 51.2 & 0.6 \\
\hline & aug-cc-pVTZ & $9.4 \mathrm{E}-03$ & $-8.1 \mathrm{E}-03$ & 0.524 & 0.259 & -1 & 52 & -1 & 81 & 48.5 & 50.9 & 0.6 \\
\hline \multirow{4}{*}{ M06-2X } & $\mathrm{ma}^{\mathrm{TZVP}}{ }^{a}$ & $7.8 \mathrm{E}-03$ & $-4.5 \mathrm{E}-03$ & 0.424 & 0.084 & 0 & 68 & -1 & 67 & 58.3 & 41.2 & 0.5 \\
\hline & ma-QZVP & $9.3 \mathrm{E}-03$ & $-7.9 \mathrm{E}-03$ & 0.607 & 0.344 & -1 & 67 & -1 & 94 & 40.6 & 58.4 & 1.0 \\
\hline & cc-pVTZ & $9.4 \mathrm{E}-03$ & $-8.3 \mathrm{E}-03$ & 0.609 & 0.345 & -1 & 67 & -1 & 94 & 40.6 & 58.4 & 1.1 \\
\hline & aug-cc-pVTZ & $9.5 \mathrm{E}-03$ & $-8.3 \mathrm{E}-03$ & 0.609 & 0.346 & -1 & 68 & -1 & 94 & 40.5 & 58.5 & 1.0 \\
\hline \multirow{4}{*}{$\mathrm{HF}$} & ma-TZVP & $7.8 \mathrm{E}-03$ & $-4.7 \mathrm{E}-03$ & 0.593 & 0.337 & -1 & 66 & -1 & 90 & 41.5 & 57.9 & 0.6 \\
\hline & ma-QZVP & $9.6 \mathrm{E}-03$ & $-8.5 \mathrm{E}-03$ & 0.726 & 0.504 & -1 & 92 & -1 & 100 & 28.7 & 70.5 & 0.9 \\
\hline & cc-pVTZ & $9.7 \mathrm{E}-03$ & $-8.7 \mathrm{E}-03$ & 0.719 & 0.494 & -1 & 91 & -1 & 100 & 29.4 & 69.8 & 0.8 \\
\hline & aug-cc-pVTZ & $9.7 \mathrm{E}-03$ & $-8.7 \mathrm{E}-03$ & 0.724 & 0.502 & -1 & 92 & -1 & 100 & 28.8 & 70.3 & 0.9 \\
\hline \multirow{2}{*}{ MP2 } & ma-TZVP & $8.0 \mathrm{E}-03$ & $-4.8 \mathrm{E}-03$ & 0.550 & 0.291 & & & & & & & \\
\hline & aug-cc-pVTZ & $1.0 \mathrm{E}-02$ & $-9.1 \mathrm{E}-03$ & 0.700 & 0.470 & & & & & & & \\
\hline
\end{tabular}

\footnotetext{
${ }^{a}$ Two closely separated NNAs are found for this basis set $\left(N_{\mathrm{NNA}}\right.$ and $\lambda_{\mathrm{NNA}}$ correspond to the sum of both NNAs).
} 


\section{TCNQNa $_{2}$}

The results of the ground state of TCNQNa $2\left({ }^{3} B_{1}\right)$ are collected in Table 6. In this case, the maTZVP basis set of sodium contains some $d$ and some extra $p$ functions with lower exponents, which help to describe the NNAs but are not sufficient to provide a description that matches the results obtained with the aug-cc-pVTZ basis set. The values of the density and its Laplacian at the NNA are very similar with both basis sets, but the population and, especially, the localization index are more sensitive to the quality of the basis set.

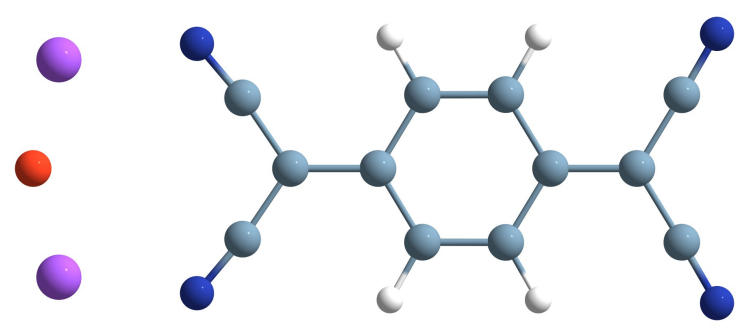

Figure 3: Geometry of TCNQNa 2 optimized at the CAM-B3LYP/ma-TZVP level of theory. The NNA position is indicated with a red ball.

As compared to $\mathrm{TCNQLi}_{2}, \mathrm{TCNQNa}_{2}$ has lower electron numbers and less localized electrons in the NNA. In the former case, more than $50 \%$ of the electrons in the NNA basin were localized, whereas for TCNQNa 2 this number is about $25 \%$ for the studied DFAs and below $50 \%$ for HF and MP2. In fact, regardless the method or basis set employed in the calculation, the probability of finding no electron in the NNA basin is clearly larger than the probability of having one or more electrons. For this molecule, the topological features obtained with the MP2 wavefunction are much closer to the values obtained at the HF level of theory, suggesting that all DFAs underestimate the electride character of this molecule. According to HF, the probability of having one or more electrons is $49 \%$, which is quite high. This result is in line with the EOS analysis at the same level of theory, which attributes different oxidation states, 0 or -1 , depending on the number of fragments used. In this sense, this molecule is a borderline situation between a zero-electron and a one-electron molecular electride. 
Table 6: Results of the QTAIM partitioning, EOS, and EDF analyses for TCNQNa2. For a full description, see Table 5.

\begin{tabular}{|c|c|c|c|c|c|c|c|c|c|c|c|c|}
\hline Method & Basis & $\rho\left(\mathbf{r}_{\mathrm{NNA}}\right)$ & $\nabla^{2} \rho\left(\mathbf{r}_{\mathrm{NNA}}\right)$ & $N_{\mathrm{NNA}}$ & $\lambda_{\mathrm{NNA}}$ & EOS[1] & RI & EOS[2] & RI & $\mathrm{P}_{0}$ & $\mathrm{P}_{1}$ & $\mathrm{P}_{2}$ \\
\hline \multirow{2}{*}{ CAM-B3LYP } & ma-TZVP & $6.9 \mathrm{E}-03$ & $-4.4 \mathrm{E}-03$ & 0.213 & 0.044 & 0 & 100 & 0 & 66 & 78.9 & 21.0 & 0.0 \\
\hline & aug-cc-pVTZ & 7.1E-03 & $-4.9 \mathrm{E}-03$ & 0.265 & 0.068 & 0 & 98 & 0 & 58 & 73.7 & 26.2 & 0.1 \\
\hline \multirow{2}{*}{ B3LYP } & ma-TZVP & $6.6 \mathrm{E}-03$ & $-4.1 \mathrm{E}-03$ & 0.170 & 0.028 & 0 & 100 & 0 & 72 & 83.2 & 16.8 & 0.0 \\
\hline & aug-cc-pVTZ & $6.8 \mathrm{E}-03$ & $-4.6 \mathrm{E}-03$ & 0.217 & 0.045 & 0 & 100 & 0 & 65 & 78.6 & 21.3 & 0.0 \\
\hline \multirow{2}{*}{ M06-2X } & ma-TZVP & $6.7 \mathrm{E}-03$ & $-4.0 \mathrm{E}-03$ & 0.236 & 0.053 & 0 & 100 & 0 & 62 & 76.7 & 23.2 & 0.1 \\
\hline & aug-cc-pVTZ & $6.9 \mathrm{E}-03$ & $-4.5 \mathrm{E}-03$ & 0.241 & 0.054 & 0 & 100 & 0 & 61 & 76.3 & 23.6 & 0.1 \\
\hline \multirow{2}{*}{$\mathrm{HF}$} & ma-TZVP & $7.1 \mathrm{E}-03$ & $-5.2 \mathrm{E}-03$ & 0.443 & 0.191 & 0 & 63 & -1 & 68 & 56.2 & 43.7 & 0.2 \\
\hline & aug-cc-pVTZ & 7.1E-03 & $-5.4 \mathrm{E}-03$ & 0.495 & 0.238 & 0 & 52 & -1 & 75 & 51.0 & 48.8 & 0.2 \\
\hline \multirow{2}{*}{ MP2 } & ma-TZVP & $7.3 \mathrm{E}-03$ & $-5.3 \mathrm{E}-03$ & 0.418 & 0.171 & & & & & & & \\
\hline & aug-cc-pVTZ & 7.4E-03 & $-5.6 \mathrm{E}-03$ & 0.465 & 0.212 & & & & & & & \\
\hline
\end{tabular}




\section{Li@calix[4]pyrrole and Na@calix[4]pyrrole}

The results of the ground state of Li@calix[4]pyrrole ${ }^{45,70,87}\left({ }^{2} A_{1}\right)$ and Na@calix[4]pyrrole ${ }^{45,87}$ $\left({ }^{2} A_{1}\right)$ are collected in Tables 7 and 8 , respectively. Unlike TCNQLi 2 , in this case, ma-TZVP provides qualitatively similar results to aug-cc-pVTZ because the Li and $\mathrm{N}$ atoms are closer to the NNA, therefore, the $p$ functions centered in $\mathrm{Li}$ (as well as the diffuse functions in the neighboring $\mathrm{N}$ atoms) provide a better description of the NNA.

CAM-B3LYP density descriptors are clearly closer to the MP2 ones, and hence we will focus on the EOS and EDF analyses at the CAM-B3LYP/aug-cc-pVTZ level of theory. The average population and the localized electrons of the NNA basin are rather low, in agreement with the zero oxidation state and the high RI assigned by the EOS analysis. The EDF analysis confirms that the probability of having zero electrons in the NNA basin is the largest one, although it also reveals a non-negligible probability of $26.3 \%$ and $16.5 \%$ of having one or more electrons in the NNA basin of Li@calix[4]pyrrole and Na@calix[4]pyrrole, respectively. Both molecules can be thus classified low-electron-number electrides.
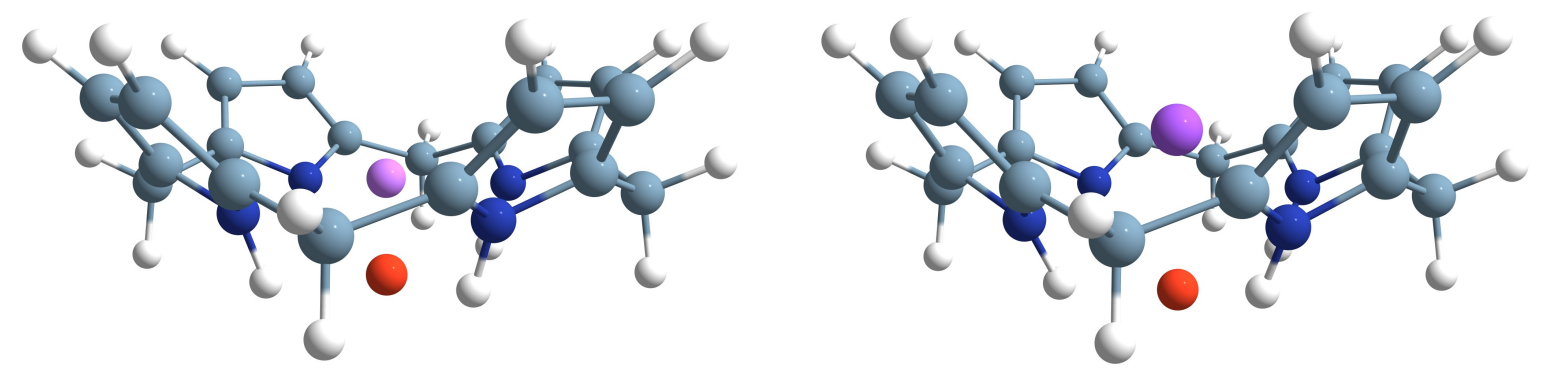

Figure 4: Geometries of Li@calix[4]pyrrole and $\mathrm{Na} @$ calix[4]pyrrole optimized at the CAM$\mathrm{B} 3 \mathrm{LYP} / \mathrm{ma}-\mathrm{TZVP}$ level of theory. The NNA position is indicated with a red ball. 
Table 7: Results of the QTAIM partitioning, EOS, and EDF analyses for Li@ calix[4]pyrrole. For a full description, see Table 5.

\begin{tabular}{|c|c|c|c|c|c|c|c|c|c|c|c|c|}
\hline Method & Basis & $\rho\left(\mathbf{r}_{\mathrm{NNA}}\right)$ & $\nabla^{2} \rho\left(\mathbf{r}_{\mathrm{NNA}}\right)$ & $N_{\mathrm{NNA}}$ & $\lambda_{\mathrm{NNA}}$ & EOS[1] & RI & EOS[2] & RI & $\mathrm{P}_{0}$ & $\mathrm{P}_{1}$ & $\mathrm{P}_{2}$ \\
\hline \multirow{2}{*}{ CAM-B3LYP } & בma-TZVP & $7.6 \mathrm{E}-03$ & $-4.0 \mathrm{E}-03$ & 0.291 & 0.079 & 0 & 94 & 0 & 91 & 71.5 & 28.3 & 0.2 \\
\hline & aug-cc-pVTZ & $8.0 \mathrm{E}-03$ & $-5.2 \mathrm{E}-03$ & 0.269 & 0.067 & 0 & 98 & 0 & 95 & 73.7 & 26.2 & 0.1 \\
\hline \multirow{2}{*}{ B3LYP } & ma-TZVP & $6.9 \mathrm{E}-03$ & $-3.2 \mathrm{E}-03$ & 0.215 & 0.043 & 0 & 100 & 0 & 100 & 78.9 & 21.0 & 0.1 \\
\hline & aug-cc-pVTZ & 7.2E-03 & $-4.3 \mathrm{E}-03$ & 0.193 & 0.035 & 0 & 100 & 0 & 100 & 81.0 & 18.9 & 0.1 \\
\hline \multirow{2}{*}{ M06-2X } & ma-TZVP & $7.0 \mathrm{E}-03$ & $-2.9 \mathrm{E}-03$ & 0.195 & 0.035 & 0 & 100 & 0 & 100 & 81.0 & 19.0 & 0.1 \\
\hline & aug-cc-pVTZ & 7.3E-03 & $-4.1 \mathrm{E}-03$ & 0.177 & 0.028 & 0 & 100 & 0 & 100 & 82.8 & 17.1 & 0.1 \\
\hline \multirow{2}{*}{$\mathrm{HF}$} & ma-TZVP & $7.6 \mathrm{E}-03$ & $-5.2 \mathrm{E}-03$ & 0.518 & 0.250 & -0.5 & 100 & -1 & 52 & 49.3 & 50.0 & 0.7 \\
\hline & aug-cc-pVTZ & $7.8 \mathrm{E}-03$ & $-5.8 \mathrm{E}-03$ & 0.511 & 0.245 & 0 & 51 & -1 & 51 & 49.8 & 49.5 & 0.6 \\
\hline \multirow{2}{*}{ MP2 } & ma-TZVP & $7.7 \mathrm{E}-03$ & $-4.5 \mathrm{E}-03$ & 0.321 & 0.100 & & & & & & & \\
\hline & aug-cc-pVTZ & 8.2E-03 & $-5.6 \mathrm{E}-03$ & 0.288 & 0.082 & & & & & & & \\
\hline
\end{tabular}


Table 8: Results of the QTAIM partitioning, EOS, and EDF analyses for Na@ calix[4]pyrrole. For a full description, see Table 5.

\begin{tabular}{|c|c|c|c|c|c|c|c|c|c|c|c|c|}
\hline Method & Basis & $\rho\left(\mathbf{r}_{\mathrm{NNA}}\right)$ & $\nabla^{2} \rho\left(\mathbf{r}_{\mathrm{NNA}}\right)$ & $N_{\mathrm{NNA}}$ & $\lambda_{\mathrm{NNA}}$ & EOS[1] & RI & EOS[2] & RI & $\mathrm{P}_{0}$ & $\mathrm{P}_{1}$ & $\mathrm{P}_{2}$ \\
\hline \multirow{2}{*}{ CAM-B3LYP } & ma-TZVP & 5.9E-03 & $-2.6 \mathrm{E}-03$ & 0.169 & 0.027 & 0 & 100 & 0 & 100 & 83.3 & 16.7 & 0.1 \\
\hline & aug-cc-pVTZ & $6.0 \mathrm{E}-03$ & $-2.6 \mathrm{E}-03$ & 0.167 & 0.026 & 0 & 100 & 0 & 100 & 83.5 & 16.4 & 0.1 \\
\hline \multirow{2}{*}{ B3LYP } & ma-TZVP & $5.3 \mathrm{E}-03$ & $-2.0 \mathrm{E}-03$ & 0.094 & 0.008 & 0 & 100 & 0 & 100 & 90.8 & 9.2 & 0.0 \\
\hline & aug-cc-pVTZ & $5.3 \mathrm{E}-03$ & $-2.0 \mathrm{E}-03$ & 0.086 & 0.007 & 0 & 100 & 0 & 100 & 91.5 & 8.5 & 0.0 \\
\hline \multirow{2}{*}{ M06-2X } & ma-TZVP & $5.7 \mathrm{E}-03$ & $-2.2 \mathrm{E}-03$ & 0.100 & 0.009 & 0 & 100 & 0 & 100 & 90.3 & 9.7 & 0.0 \\
\hline & aug-cc-pVTZ & $5.5 \mathrm{E}-03$ & $-1.8 \mathrm{E}-03$ & 0.062 & 0.004 & 0 & 100 & 0 & 100 & 94.0 & 6.0 & 0.0 \\
\hline \multirow{2}{*}{$\mathrm{HF}$} & ma-TZVP & $5.8 \mathrm{E}-03$ & $-3.1 \mathrm{E}-03$ & 0.448 & 0.191 & 0 & 63 & 0 & 62 & 56.0 & 43.7 & 0.2 \\
\hline & aug-cc-pVTZ & $6.0 \mathrm{E}-03$ & $-3.4 \mathrm{E}-03$ & 0.484 & 0.224 & 0 & 55 & 0 & 55 & 52.4 & 47.3 & 0.2 \\
\hline \multirow{2}{*}{ MP2 } & ma-TZVP & $6.2 \mathrm{E}-03$ & $-3.0 \mathrm{E}-03$ & 0.202 & 0.041 & & & & & & & \\
\hline & aug-cc-pVTZ & $6.4 \mathrm{E}-03$ & $-3.0 \mathrm{E}-03$ & 0.195 & 0.039 & & & & & & & \\
\hline
\end{tabular}




\section{$\mathrm{TCNENa}_{3}$ and $\mathrm{TCNENa}_{4}(\mathrm{II})$}

The results for the ground state of $\mathrm{TCNENa}_{3}\left({ }^{2} A\right)$ and $\mathrm{TCNENa}_{4}(\mathrm{II})\left({ }^{3} B_{3}\right)$ are collected in Tables 9 and 10, respectively. Both compounds were recently classified as molecular electrides. ${ }^{90}$ The former presents a Na-Na pair between which we can locate a NNA, whereas the latter has two NaNa pairs, giving rise to two symmetrically-equivalent NNAs (see Figure 5). In this case, we will discuss the HF results because they provide the best agreement with the MP2 data. According to the topological analysis of the electron density, the oxidation state analysis, and electron distribution functions, both molecules have qualitatively the same electride character of $\mathrm{TCNQNa} 2$, i.e., they can be considered borderline situations between zero- and one-electron molecular electrides.
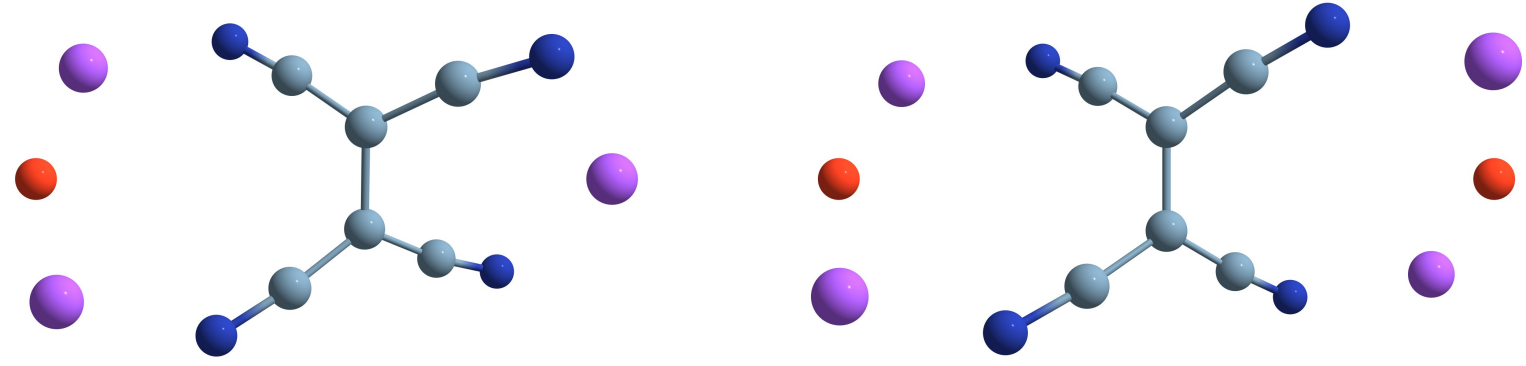

Figure 5: Geometries of $\mathrm{TCNENa}_{3}$ and $\mathrm{TCNENa}_{4}$ (II) optimized at the CAM-B3LYP/ma-TZVP level of theory. The NNA position is indicated with a red ball. 
Table 9: Results of the QTAIM partitioning, EOS, and EDF analyses for TCNENa3. For a full description, see Table 5.

\begin{tabular}{|c|c|c|c|c|c|c|c|c|c|c|c|c|}
\hline Method & Basis & $\rho\left(\mathbf{r}_{\mathrm{NNA}}\right)$ & $\nabla^{2} \rho\left(\mathbf{r}_{\mathrm{NNA}}\right)$ & $N_{\mathrm{NNA}}$ & $\lambda_{\mathrm{NNA}}$ & EOS[1] & RI & EOS[2] & RI & $\mathrm{P}_{0}$ & $\mathrm{P}_{1}$ & $\mathrm{P}_{2}$ \\
\hline \multirow{2}{*}{ CAM-B3LYP } & ma-TZVP & $7.0 \mathrm{E}-03$ & $-4.4 \mathrm{E}-03$ & 0.204 & 0.040 & 0 & 100 & 0 & 68 & 79.8 & 20.2 & $\overline{0.0}$ \\
\hline & aug-cc-pVTZ & 7.2E-03 & $-4.9 \mathrm{E}-03$ & 0.268 & 0.069 & 0 & 97 & 0 & 58 & 73.5 & 26.5 & 0.1 \\
\hline \multirow{2}{*}{ B3LYP } & ma-TZVP & $6.7 \mathrm{E}-03$ & $-4.1 \mathrm{E}-03$ & 0.162 & 0.025 & 0 & 100 & 0 & 74 & 84.0 & 16.0 & 0.0 \\
\hline & aug-cc-pVTZ & $6.9 \mathrm{E}-03$ & $-4.5 \mathrm{E}-03$ & 0.218 & 0.046 & 0 & 100 & 0 & 66 & 78.5 & 21.5 & 0.0 \\
\hline \multirow{2}{*}{ M06-2X } & ma-TZVP & $6.8 \mathrm{E}-03$ & $-4.0 \mathrm{E}-03$ & 0.211 & 0.040 & 0 & 100 & 0 & 67 & 79.3 & 20.6 & 0.2 \\
\hline & aug-cc-pVTZ & 7.1E-03 & $-4.6 \mathrm{E}-03$ & 0.228 & 0.047 & 0 & 100 & 0 & 64 & 77.6 & 22.2 & 0.2 \\
\hline \multirow{2}{*}{$\mathrm{HF}$} & ma-TZVP & $7.1 \mathrm{E}-03$ & $-5.2 \mathrm{E}-03$ & 0.438 & 0.187 & 0 & 64 & -1 & 66 & 56.6 & 43.3 & 0.1 \\
\hline & aug-cc-pVTZ & 7.2E-03 & $-5.4 \mathrm{E}-03$ & 0.495 & 0.238 & 0 & 52 & -1 & 75 & 51.0 & 48.8 & 0.2 \\
\hline \multirow{2}{*}{ MP2 } & ma-TZVP & $7.0 \mathrm{E}-03$ & $-5.0 \mathrm{E}-03$ & 0.410 & 0.165 & & & & & & & \\
\hline & aug-cc-pVTZ & 7.1E-03 & $-5.3 \mathrm{E}-03$ & 0.464 & 0.211 & & & & & & & \\
\hline
\end{tabular}


Table 10: Results of the QTAIM partitioning, EOS, and EDF analyses for TCNENa4(II). For the a full description, see Table 5.

\begin{tabular}{|c|c|c|c|c|c|c|c|c|c|c|c|c|}
\hline Method & Basis & $\rho\left(\mathbf{r}_{\mathrm{NNA}}\right)$ & $\nabla^{2} \rho\left(\mathbf{r}_{\mathrm{NNA}}\right)$ & $N_{\mathrm{NNA}}$ & $\lambda_{\mathrm{NNA}}$ & EOS[1] & RI & EOS[2] & RI & $\mathrm{P}_{0}$ & $\mathrm{P}_{1}$ & $\mathrm{P}_{2}$ \\
\hline \multirow{2}{*}{ CAM-B3LYP } & ma-TZVP & $7.0 \mathrm{E}-03$ & $\begin{array}{c}-4.3 \mathrm{E}-03 \\
\end{array}$ & 0.202 & 0.040 & 0 & 100 & 0 & 68 & 80.0 & 20.0 & 0.0 \\
\hline & aug-cc-pVTZ & 7.2E-03 & $-4.9 \mathrm{E}-03$ & 0.266 & 0.068 & 0 & 98 & 0 & 59 & 73.6 & 26.3 & 0.1 \\
\hline \multirow{2}{*}{ B3LYP } & ma-TZVP & $6.7 \mathrm{E}-03$ & $-4.0 \mathrm{E}-03$ & 0.159 & 0.024 & 0 & 100 & 0 & 74 & 84.3 & 15.7 & 0.0 \\
\hline & aug-cc-pVTZ & $6.9 \mathrm{E}-03$ & $-4.5 \mathrm{E}-03$ & 0.215 & 0.045 & 0 & 100 & 0 & 66 & 78.7 & 21.2 & 0.0 \\
\hline \multirow{2}{*}{ M06-2X } & ma-TZVP & $6.8 \mathrm{E}-03$ & $-4.0 \mathrm{E}-03$ & 0.211 & 0.041 & 0 & 100 & 0 & 67 & 79.2 & 20.6 & 0.2 \\
\hline & aug-cc-pVTZ & 7.1E-03 & $-4.6 \mathrm{E}-03$ & 0.226 & 0.046 & 0 & 100 & 0 & 65 & 77.8 & 22.0 & 0.2 \\
\hline \multirow{2}{*}{$\mathrm{HF}$} & ma-TZVP & $7.1 \mathrm{E}-03$ & $-5.2 \mathrm{E}-03$ & 0.439 & 0.188 & 0 & 63 & -1 & 67 & 56.5 & 43.4 & 0.1 \\
\hline & aug-cc-pVTZ & $7.2 \mathrm{E}-03$ & $-5.4 \mathrm{E}-03$ & 0.495 & 0.239 & 0 & 52 & -1 & 75 & 51.0 & 48.9 & 0.2 \\
\hline \multirow{2}{*}{ MP2 } & ma-TZVP & $7.0 \mathrm{E}-03$ & $-5.0 \mathrm{E}-03$ & 0.411 & 0.166 & & & & & & & \\
\hline & aug-cc-pVTZ & 7.1E-03 & $-5.2 \mathrm{E}-03$ & 0.465 & 0.211 & & & & & & & \\
\hline
\end{tabular}




\section{$\mathbf{M g}_{2} \mathbf{E P}$}

The results of the ground state of $\operatorname{Mg}_{2} \mathrm{EP}\left({ }^{1} A_{1}\right)$ are collected in Table 11. This molecule was classified as a molecular electride by Chattaraj and co-workers ${ }^{91}$ and it displays a NNA between the two Mg atoms (see Figure 6). In this case, all density functional approximations give very similar values, however, MP2 results lie in between HF and CAM-B3LYP values. The average number of electrons in the NNA basin is quite large compared to previous molecules. The EOS analysis assigns two different oxidation states, 0 or -2 , depending on the partition scheme. Due to the spin symmetry of the molecule (this is a closed-shell system), the EOS cannot assign an oxidation state of -1 to the NNA basin. The electron distribution analysis reveals an important difference with previous molecules: the probability of having two electrons in the NNA is not negligible and ranges between 11-25\% depending on the level of theory. As we shall discuss later, this feature will be important in order to compare the EOS and EDF analyses. Interestingly, regardless of the methodology employed in the calculation, the probability of having more than one electron at the NNA is always higher than $50 \%$ and the most likely situation is that of having only one electron at the NNA. In this case, there is an obvious disagreement between EOS and EDF, regardless the partition employed in the former analysis, but we can speculate that this molecule is at least a one-electron electride.

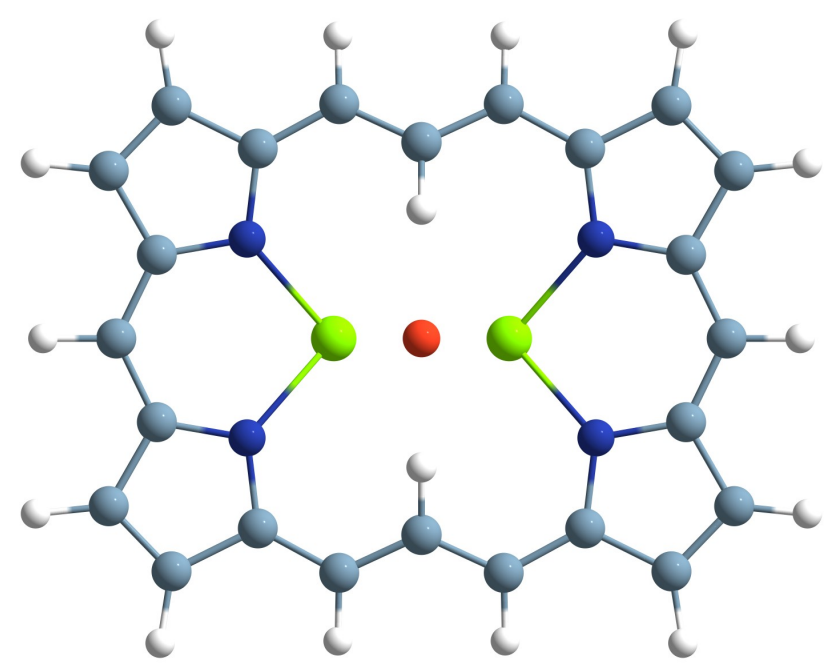

Figure 6: Geometry of $\mathrm{Mg}_{2}$ EP optimized at the CAM-B3LYP/ma-TZVP level of theory. The NNA position is indicated with a red ball. 
Table 11: Results of the QTAIM partitioning, EOS, and EDF analyses for $\mathrm{Mg}_{2}$ EP. For a full description, see Table 5.

\begin{tabular}{|c|c|c|c|c|c|c|c|c|c|c|c|c|}
\hline Method & Basis & $\rho\left(\mathbf{r}_{\mathrm{NNA}}\right)$ & $\nabla^{2} \rho\left(\mathbf{r}_{\mathrm{NNA}}\right)$ & $N_{\mathrm{NNA}}$ & $\lambda_{\mathrm{NNA}}$ & EOS[1] & RI & EOS[2] & RI & $\mathrm{P}_{0}$ & $\mathrm{P}_{1}$ & $\mathrm{P}_{2}$ \\
\hline \multirow{2}{*}{ CAM-B3LYP } & ma-TZVP & $3.2 \mathrm{E}-02$ & $-3.8 \mathrm{E}-02$ & 0.722 & 0.229 & 0 & 82 & -2 & 59 & 42.1 & 44.7 & 12.8 \\
\hline & aug-cc-pVTZ & $3.3 \mathrm{E}-02$ & $-3.9 \mathrm{E}-02$ & 0.746 & 0.244 & 0 & 80 & -2 & 60 & 40.6 & 45.3 & 13.6 \\
\hline \multirow{2}{*}{ B3LYP } & ma-TZVP & $3.2 \mathrm{E}-02$ & $-3.6 \mathrm{E}-02$ & 0.677 & 0.201 & 0 & 87 & -2 & 56 & 44.9 & 43.4 & 11.3 \\
\hline & aug-cc-pVTZ & $3.2 \mathrm{E}-02$ & $-3.8 \mathrm{E}-02$ & 0.712 & 0.222 & 0 & 83 & -2 & 58 & 42.7 & 44.4 & 12.4 \\
\hline \multirow{2}{*}{ M06-2X } & ma-TZVP & $3.1 \mathrm{E}-02$ & $-3.6 \mathrm{E}-02$ & 0.705 & 0.219 & 0 & 84 & -2 & 58 & 43.1 & 44.3 & 12.2 \\
\hline & aug-cc-pVTZ & $3.1 \mathrm{E}-02$ & $-3.7 \mathrm{E}-02$ & 0.701 & 0.216 & 0 & 84 & -2 & 58 & 43.4 & 44.1 & 12.1 \\
\hline \multirow{2}{*}{$\mathrm{HF}$} & ma-TZVP & $3.4 \mathrm{E}-02$ & $-4.3 \mathrm{E}-02$ & 1.018 & 0.460 & 0 & 54 & -2 & 79 & 25.8 & 48.8 & 24.3 \\
\hline & aug-cc-pVTZ & $3.4 \mathrm{E}-02$ & $-4.3 \mathrm{E}-02$ & 1.030 & 0.470 & 0 & 53 & -2 & 79 & 25.3 & 48.7 & 24.8 \\
\hline \multirow{2}{*}{ MP2 } & ma-TZVP & $3.0 \mathrm{E}-02$ & $-3.5 \mathrm{E}-02$ & 0.835 & 0.332 & & & & & & & \\
\hline & aug-cc-pVTZ & $3.1 \mathrm{E}-02$ & $-3.6 \mathrm{E}-02$ & 0.876 & 0.366 & & & & & & & \\
\hline
\end{tabular}


$\mathbf{M g}_{2} @ \mathbf{C}_{60}$

The results for the ground state of $\mathrm{Mg}_{2} @ \mathrm{C}_{60}\left({ }^{1} A_{g}\right)$ are collected in Table 12. This molecule was also classified as a molecular electride by Chattaraj and co-workers ${ }^{88}$ because, among other properties, ${ }^{45}$ it presents a NNA between both Mg atoms (see Figure 7). In this case, all density functional approximations provide very similar results to MP2, whereas HF clearly overestimates the electride character of the molecule. The EOS analysis also suggests the oxidation state of the NNA is either zero or -2 , depending on the partition employed. The oxidation state of -1 is also discarded by the EOS analysis due to the spin symmetry of the molecule. On the other hand, the probability of finding at least one electron at the NNA basin is larger (56-59\% depending on the DFA) than the probability of finding no electron, and the probability of finding exactly two electrons is not negligible (11-13\%). The situation in which we have only one electron is the most likely scenario if one has to choose between the three possibilities, although, according to the EDF analysis, no possibility can be ruled out. Hence, we are deemed to conclude that $\mathrm{Mg}_{2} @ \mathrm{C}_{60}$ is at least a one-electron electride.

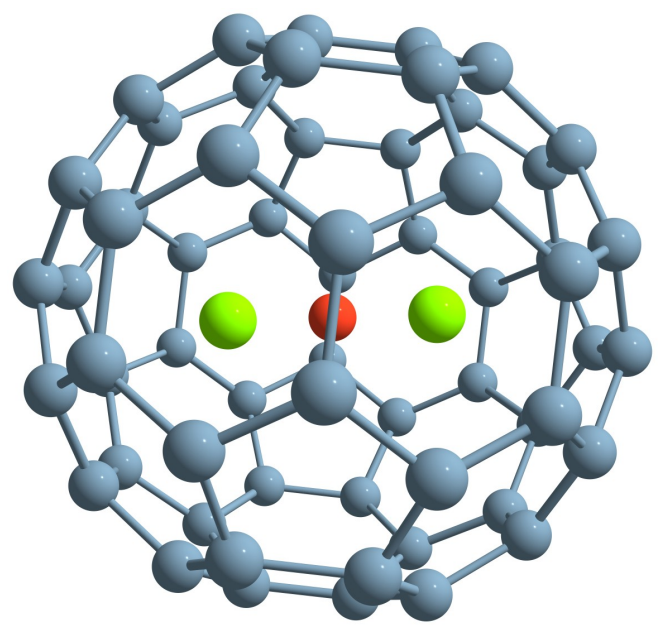

Figure 7: Geometry of $\mathrm{Mg}_{2} @ \mathrm{C}_{60}$ optimized at the CAM-B3LYP/ma-TZVP level of theory. The NNA position is indicated with a red ball. 
Table 12: Results of the QTAIM partitioning, EOS, and EDF analyses for $\mathrm{Mg}_{2} @ \mathrm{C}_{60}$. For a full description, see Table 5.

\begin{tabular}{|c|c|c|c|c|c|c|c|c|c|c|c|c|}
\hline Method & Basis & $\rho\left(\mathbf{r}_{\mathrm{NNA}}\right)$ & $\nabla^{2} \rho\left(\mathbf{r}_{\mathrm{NNA}}\right)$ & $N_{\mathrm{NNA}}$ & $\lambda_{\mathrm{NNA}}$ & EOS[1] & RI & EOS[2] & RI & $\mathrm{P}_{0}$ & $\mathrm{P}_{1}$ & $\mathrm{P}_{2}$ \\
\hline \multirow{2}{*}{ CAM-B3LYP } & ma-TZVP & $4.0 \mathrm{E}-02$ & $-5.0 \mathrm{E}-02$ & 0.699 & 0.211 & 0 & 85 & -2 & $\overline{58}$ & 43.8 & 43.9 & 11.9 \\
\hline & aug-cc-pVTZ & $4.0 \mathrm{E}-02$ & $-5.5 E-02$ & 0.738 & 0.234 & 0 & 82 & -2 & 61 & 41.4 & 44.9 & 13.1 \\
\hline \multirow{2}{*}{ B3LYP } & ma-TZVP & $3.9 \mathrm{E}-02$ & $-5.0 \mathrm{E}-02$ & 0.685 & 0.202 & 0 & 87 & -2 & 57 & 44.8 & 43.4 & 11.4 \\
\hline & aug-cc-pVTZ & $4.0 \mathrm{E}-02$ & $-5.4 \mathrm{E}-02$ & 0.732 & 0.229 & 0 & 82 & -2 & 60 & 41.9 & 44.7 & 12.9 \\
\hline \multirow{2}{*}{ M06-2X } & ma-TZVP & $3.7 \mathrm{E}-02$ & $-4.6 \mathrm{E}-02$ & 0.687 & 0.203 & 0 & 86 & -2 & 58 & 44.7 & 43.5 & 11.4 \\
\hline & aug-cc-pVTZ & $3.8 \mathrm{E}-02$ & $-5.2 \mathrm{E}-02$ & 0.704 & 0.212 & 0 & 85 & -2 & 59 & 43.7 & 43.9 & 12.0 \\
\hline \multirow{2}{*}{$\mathrm{HF}$} & ma-TZVP & $4.2 \mathrm{E}-02$ & $-5.9 \mathrm{E}-02$ & 0.971 & 0.404 & 0 & 60 & -2 & 75 & 28.6 & 48.3 & 21.9 \\
\hline & aug-cc-pVTZ & $4.2 \mathrm{E}-02$ & $-6.2 \mathrm{E}-02$ & 0.984 & 0.412 & 0 & 59 & -2 & 76 & 28.0 & 48.3 & 22.3 \\
\hline MP2 & ma-TZVP & $3.3 \mathrm{E}-02$ & $-3.7 \mathrm{E}-02$ & 0.691 & 0.215 & & & & & & & \\
\hline
\end{tabular}


$e @ \mathrm{C}_{60} \mathrm{~F}_{60}$

Finally, we study the ground state of $e @ \mathrm{C}_{60} \mathrm{~F}_{60} \quad\left({ }^{2} A_{g}\right)$, which was previously assigned a weak electride character. ${ }^{45}$ The results are collected in Table 13. This is the largest molecule studied in this paper and its size prevents the use of large basis sets. One can identify a NNA in the middle of the fullerene cage (see Figure 8). Following previous studies, ${ }^{45,92}$ we have augmented mediumsized basis sets with some additional functions placed at the center of cage in order to provide a good description of the NNA. Namely, we have added four uncontracted diffuse functions of $s$ and $p$ - type with exponents $1.68714478 \cdot 10^{-n}(n=1-4)$. These basis sets have been labeled as $+\mathrm{DF}$ (see Table 13). For this molecule, the results are quite sensitive to the level of theory employed in the calculation. Compared to MP2, B3LYP clearly underestimates the electride character, whereas HF significantly overestimates it. CAM-B3LYP results agree quite well with the MP2 values, suggesting that there is a rather small number of electrons in NNA basin. The EOS analysis clearly assigns a zero oxidation state, in line with the large value of the probability of finding no electron at the NNA (67-70\%). However, there is a non-negligible probability of finding one electron (30$33 \%$ ), suggesting that this is a low-electron-number molecular electride.

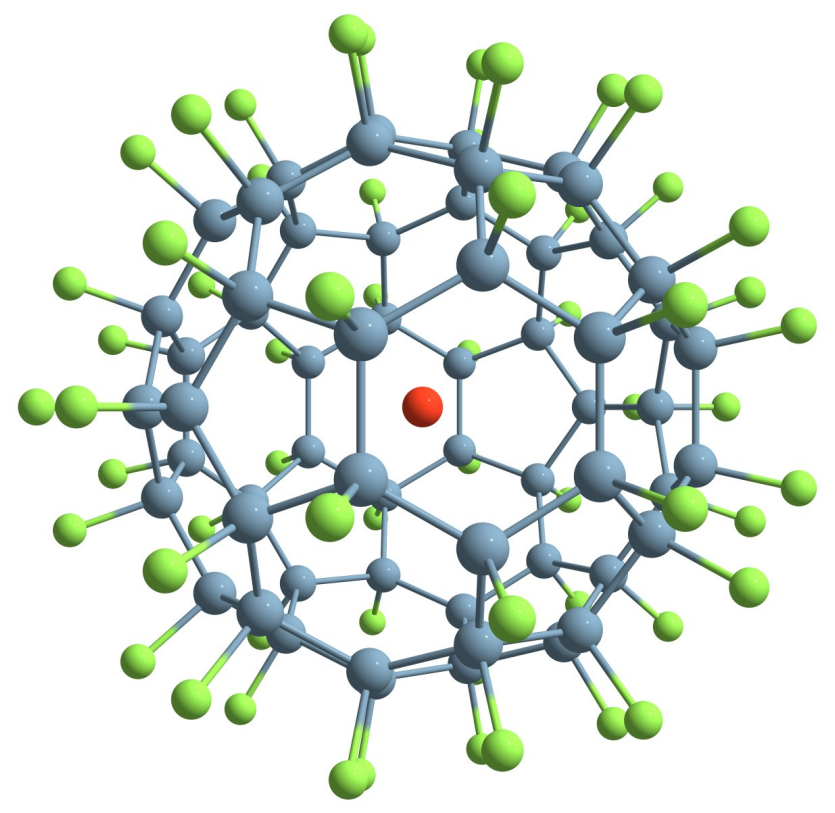

Figure 8: Geometry of $e @ \mathrm{C}_{60} \mathrm{~F}_{60}$ optimized at the CAM-B3LYP/ma-TZVP+DF level of theory. The NNA position is indicated with a red ball. 
Table 13: Results of the QTAIM partitioning, EOS, and EDF analyses for $e @ \mathrm{C}_{60} \mathrm{~F}_{60}$. For a full description, see Table 5.

\begin{tabular}{|c|c|c|c|c|c|c|c|c|c|c|}
\hline Method & Basis & $\rho\left(\mathbf{r}_{\mathrm{NNA}}\right)$ & $\nabla^{2} \rho\left(\mathbf{r}_{\mathrm{NNA}}\right)$ & $N_{\mathrm{NNA}}$ & $\lambda_{\mathrm{NNA}}$ & EOS[1] & RI & $\mathrm{P}_{0}$ & $\mathrm{P}_{1}$ & $\mathrm{P}_{2}$ \\
\hline \multirow{4}{*}{ CAM-B3LYP } & 6-31G+DF & $3.83 \mathrm{E}-03$ & $-3.55 \mathrm{E}-03$ & 0.307 & 0.087 & 0 & 90 & 70.4 & 29.6 & 0.0 \\
\hline & $6-31 G(d)+D F$ & 3.79E-03 & $-3.37 \mathrm{E}-03$ & 0.311 & 0.090 & 0 & 90 & 70.0 & 30.0 & 0.0 \\
\hline & $6-31+\mathrm{G}+\mathrm{DF}$ & $2.75 \mathrm{E}-03$ & $-9.20 \mathrm{E}-04$ & 0.336 & 0.104 & 0 & 86 & 67.7 & 32.2 & 0.0 \\
\hline & ma-TZVP+DF & $2.55 \mathrm{E}-03$ & $-6.11 E-04$ & 0.347 & 0.109 & 0 & 84 & 66.9 & 33.0 & 0.1 \\
\hline \multirow{4}{*}{ B3LYP } & 6-31G+DF & $3.09 \mathrm{E}-03$ & $-2.85 \mathrm{E}-03$ & 0.231 & 0.050 & 0 & 100 & 77.6 & 22.3 & 0.0 \\
\hline & $6-31 G(d)+D F$ & $3.08 \mathrm{E}-03$ & $-2.71 E-03$ & 0.239 & 0.053 & 0 & 100 & 77.0 & 23.0 & 0.0 \\
\hline & $6-31+\mathrm{G}+\mathrm{DF}$ & $2.24 \mathrm{E}-03$ & $-7.64 \mathrm{E}-04$ & 0.243 & 0.055 & 0 & 100 & 76.3 & 23.6 & 0.1 \\
\hline & ma-TZVP+DF & $2.08 \mathrm{E}-03$ & $-5.30 \mathrm{E}-04$ & 0.259 & 0.060 & 0 & 100 & 75.4 & 24.6 & 0.0 \\
\hline \multirow{7}{*}{$\mathrm{HF}$} & 6-31G+DF & $6.56 \mathrm{E}-03$ & $-7.25 \mathrm{E}-03$ & 0.503 & 0.233 & 0 & 53 & 51.5 & 48.3 & 0.0 \\
\hline & $6-31 G(d)+D F$ & $6.40 \mathrm{E}-03$ & $-6.88 \mathrm{E}-03$ & 0.501 & 0.232 & 0 & 53 & 51.8 & 48.1 & 0.1 \\
\hline & $6-31+\mathrm{G}+\mathrm{DF}$ & 4.60E-03 & $-2.46 \mathrm{E}-03$ & 0.565 & 0.293 & -1 & 58 & 45.6 & 54.1 & 0.3 \\
\hline & ma-TZVP+DF & 4.26E-03 & $-1.65 \mathrm{E}-03$ & 0.593 & 0.317 & -1 & 62 & 43.3 & 56.1 & 0.5 \\
\hline & cc-pVDZ+DF & $6.08 \mathrm{E}-03$ & $-6.35 \mathrm{E}-03$ & 0.479 & 0.210 & 0 & 58 & 54.1 & 45.8 & 0.1 \\
\hline & mix-cc-pVDZ+DF & 4.39E-03 & $-2.08 \mathrm{E}-03$ & 0.546 & 0.274 & -1 & 55 & 47.0 & 52.3 & 0.7 \\
\hline & jun-cc-pVDZ+DF & $4.31 \mathrm{E}-03$ & $-1.79 \mathrm{E}-03$ & 0.556 & 0.285 & -1 & 57 & 46.4 & 53.4 & 0.2 \\
\hline \multirow{4}{*}{ MP2 } & $6-31 \mathrm{G}+\mathrm{DF}$ & $3.89 \mathrm{E}-03$ & $-3.17 \mathrm{E}-03$ & 0.331 & 0.107 & & & & & \\
\hline & $6-31 G(d)+D F$ & $3.43 \mathrm{E}-03$ & $-2.41 E-03$ & 0.308 & 0.095 & & & & & \\
\hline & $6-31+\mathrm{G}+\mathrm{DF}$ & $2.41 \mathrm{E}-03$ & $-1.83 \mathrm{E}-05$ & 0.351 & 0.119 & & & & & \\
\hline & cc-pVDZ+DF & $3.07 \mathrm{E}-03$ & $-1.88 \mathrm{E}-03$ & 0.273 & 0.076 & & & & & \\
\hline
\end{tabular}




\section{Discussion and Conclusions}

In the previous section, we have seen that the correct description of a molecular electride hinges on the electronic structure method employed for the analyses. First of all, the basis set employed should include sufficiently flexible functions in the atoms that are in close proximity to the NNA, otherwise, the molecular electride character can be significantly underestimated, to the point that the molecule could not be considered an electride. This is the case of ma-TZVP basis set, with which we cannot locate the NNA in some cases, whereas in other cases we got a too small number of electrons in the NNA basins.

Among the density functional approximations explored in this work, CAM-B3LYP seems to be the one in closest agreement with the reference MP2 data. This is probably due to the fact that range-separated functionals tend to reduce the delocalization error in comparison to their hybrid peers with a low percentage of HF exchange, such as B3LYP. In general, the number of electrons in the NNA basins of electrides depends on the amount of HF exchange included in the method. B3LYP usually gives the lowest average electron numbers in the NNA basins, the largest zero-electron probabilities and the lowest oxidation states. This result is in line with the large delocalization errors documented in conjugated ${ }^{82}$ and aromatic molecules. ${ }^{83-86,95}$ CAM-B3LYP and M06-2X do not suffer from large delocalization errors and often provide similar NNA electron numbers, although slightly lower than those given by MP2. On the other hand, HF, which tends to overestimate electron localization, provides the largest electron numbers in the NNA basin. This is the general trend but, in other cases, such as $\mathrm{Mg}_{2} \mathrm{EP}$, the delocalization error does not seem to be so important and all density functional approximations underestimate the electride character. One should keep in mind that some DFAs are completely inadequate to study molecular electrides. This is the case of MN15, ${ }^{99}$ which systematically fails to locate a NNA in these molecules. For the sake of completeness, we have included these results in the Supporting Information.

Several tools to analyze the electride character of molecules have been employed in this work. 
If we take as a reference criterion the probability of finding at least one electron in the NNA basin, $1-P_{0}$, we realize that there is not a clear-cut value of the electron density at the NNA or its Laplacian that can be used to clearly characterize the molecule (see Figures S2 and S3). The same can be said about the average number of electrons in the NNA and the localization index. However, as a qualitative indication, we can state that one-electron electrides $\left(1-P_{0}>0.5\right)$ usually have $N_{\mathrm{NNA}} \geq 0.5$ and $\lambda_{\mathrm{NNA}} \geq 0.2$ (see Figures S4 and S5). In most cases, the EOS analysis predicts an oxidation state in agreement with the largest probability. However, we have found some exceptions that should be analyzed in detail: $\mathrm{Mg}_{2} @ \mathrm{C}_{60}$ an $\mathrm{Mg}_{2} \mathrm{EP}$.

First of all, we will examine the EOS analysis that applies the simplest fragmentation, EOS[1], which only considers two fragments: the NNA and the rest of the molecule. Instead of the reliability index (RI), which only takes values in the range $[50 \%, 100 \%]$, we will analyze the smallest difference between the occupation of the lowest occupied effective atomic orbital (EffAO), $\lambda_{\mathrm{LO}}$, and the first unoccupied orbital, $\lambda_{\mathrm{FU}}$, i.e., $\min \left(\Delta \lambda^{\alpha}, \Delta \lambda^{\beta}\right)$. Notice that by occupied and unoccupied EffAOs, we refer to orbitals to which are and are not assigned an electron during the EOS analysis, respectively. $\Delta \lambda=\lambda_{\mathrm{LO}}-\lambda_{\mathrm{FU}}$ is actually used to calculate the RI (see Eq. 5) and, in practice, employing this measure instead of the RI will permit to distinguish cases that will be all considered $100 \%$ certain by the RI (compare Figures 9 and S1). Furthermore, $\Delta \lambda=0$ does not imply that the probability of the oxidation states assigned by the EOS analysis is $50 \%$, since $\Delta \lambda=0$ can also occur when we have systems with more than two oxidation states that have the same probability. In Figure 9, we represent the probability of finding $n$ electrons at the NNA basin, $n$ being the oxidation state predicted by the EOS analysis, against $\min \left(\Delta \lambda^{\alpha}, \Delta \lambda^{\beta}\right)$ for all the molecules and methods for which we could locate a NNA. We can clearly differentiate between two groups of molecules: types A and B. Each group shows a perfectly predictable behavior of one quantity with respect to the other. Type-B electrides correspond to calculations for which $P_{2}$ is negligible, whereas $P_{2}$ values are significant $\left(P_{2}>0.1\right)$ for type-A electrides. For type-B electrides, which are open-shell molecules, there is only one EffAO assigned to the NNA with an occupation much larger 
than zero, $\lambda$, which, has a corresponding EffAOs in the other fragment with occupation $1-\lambda$ (the other occupied and unoccupied EffAOs assigned to the rest of the molecule have occupations close to 1 and 0 , respectively). Since for single-determinant wavefunctions, if $P_{i}=0 \forall i>1, P_{0}=(1-\lambda)$ and $P_{1}=\lambda$, it is easy to prove that $P_{i}=1 / 2+1 / 2 \Delta \lambda, i$ being the oxidation state assigned by the EOS analysis (in this case, $i$ is either zero or one) and the gap being $\Delta \lambda=|1-2 \lambda|$. Indeed, the blue points in Figure 9 follow this equation. Type-A electrides are closed-shell molecules, for which $P_{2}$ is not negligible, $P_{i}=0 \forall i>2$ and, by spin symmetry, they have only two degenerate EffAOS with occupations $\lambda_{1}=\lambda_{2}=\lambda$. In this case, the probabilities can be also determined analytically for the oxidation state assigned by EOS. By spin symmetry, the EOS analysis can only assign zero or two electrons to the NNA of type-A electrides and, in either case, $P=1 / 4(\Delta \lambda+1)^{2}$, so there is also a simple relationship between the gap and the probability but, this time, there is a quadratic dependence. For $\Delta \lambda<1 / 2$, the error of neglecting the quadratic term in the calculation of $P$ leads to small errors, ranging between $0 \%$ and $6.25 \%$. For this reason, type-A electrides, which mostly have $\Delta \lambda$ values below $1 / 2$, also present a very good linear correlation between $P$ with $\Delta \lambda$ (see Figure 9).

From the latter results, some features of the EOS analysis are revealed. Since alpha and beta electrons are assigned independently, symmetry-breaking electron distributions of the fragments are not considered in the EOS analysis - this fact is reminiscent of the incompatibility ${ }^{132}$ of the local spin analysis ${ }^{133,134}$ and the EDFs. This a consequence of EOS (or local spin) considering averaged quantities, whereas EDFs are probabilities that can include symmetry-breaking situations (obviously, EDFs can be used to calculate averaged quantities that will respect the symmetry of the system, see Eq. 3). Hence, the EOS analysis on the fragment partitions of closed-shell molecules will never assign an odd number of electrons to some fragment and, therefore, there will never be an agreement between the EOS and EDFs analyses for the fragments of closed-shell molecules for which the largest $P_{i}$ corresponds to an odd $i$. 
In the following, we will discuss some advantages of using $\Delta \lambda^{\alpha} \Delta \lambda^{\beta}$ instead of RI to measure the reliability of the oxidation state provided by the EOS analysis. As stated above, the RI depends on $\min \left(\Delta \lambda^{\alpha}, \Delta \lambda^{\beta}\right)$ value (see Eq. 4). We have found a linear correspondence between $\min \left(\Delta \lambda^{\alpha}, \Delta \lambda^{\beta}\right)$ and the EDFs for some simple systems, such as type-B electrides, for which $P_{i} \approx 0 \forall i>1$ and, therefore, $\Delta \lambda^{\beta} \approx 1$. However, for the type-A electrides, the quadratic dependence of $P$ on $\Delta \lambda^{\alpha} \Delta \lambda^{\beta}$ is not negligible, and the relationship between the RI and the probability is lost in this case. For this reason, we believe that $\Delta \lambda^{\alpha} \Delta \lambda^{\beta}$ is a better measure of the uncertainty of the oxidation state assignment. In Figure 10, we display again the probability of having a number of electrons that matches the oxidation state predicted by the EOS analysis for type-A and type-B electrides against this new measure of uncertainty. For type-B molecules, as discussed above, the dependence of $P$ on $\Delta \lambda^{\alpha} \Delta \lambda^{\beta}$ is very similar to the one presented in Figure 9 because $\Delta \lambda^{\beta} \approx 1$. In this Figure, for type-A electrides, we also represent the probability of having zero, one, and two electrons in the NNA basins. For the type-A electrides, the EOS analysis always predicts a zero oxidation state. However, for several of these molecules, $P_{1}$ is larger than $P_{0}$ and the values of $\Delta \lambda^{\alpha} \Delta \lambda^{\beta}$ are really small. In fact, the latter quantity is smaller than 0.3 until the probability of having no electrons goes well beyond 50\%. In this sense, this new reliability measure seems to display small values for systems with more distributed probabilities, such as those in type-A category, and only provide very large values (close to 1.0) for cases where probability of having exactly the number of electrons indicated by the oxidation state is close to $100 \%$. Notice that the oxidation state assignment provided by the EOS analysis remains unchanged, we are only suggesting a reliability measure that better reflects the probabilities given by the EDFs,

$$
\mathrm{RM}=\Delta \lambda^{\alpha} \Delta \lambda^{\beta}
$$

RM taking values between zero and one. As an illustration, let us compare RI and RM values for $\mathrm{Mg}_{2} @ \mathrm{C}_{60}$ at the CAMB3LYP/ma-TZVP level of theory. In this case, EOS[1]=0 with RI=85\% (a highly reliable assignment), and $\operatorname{EOS}[2]=-2$ with $\mathrm{RI}=58 \%$. On other hand, $\mathrm{RM}$ is equal to 0.12 , a 
fairly small value, in better agreement with the EDFs, which state that $P_{1}$ value is very close to $P_{0}$ and $1-P_{0}>0.5$.

The second partition considered in the EOS analysis, which defines separate fragments for the metallic atoms in the molecules ( $\mathrm{Li}, \mathrm{Na}$, and $\mathrm{Mg}$ ), always provide an oxidation state equal or more negative than the first partition. If the NNA and the rest of molecule are competing for an electron, it is more likely for the NNA to win the battle when the rest of the molecule is divided into various fragments. If we disregard the situations where the quality of the basis set was dubious and HF, which clearly overestimates the localized character of the NNA, most of the discrepancies between EOS[1] and EOS[2] occurred for type-A electrides. In other words, the partition seems to be more relevant in situations where $P_{2} \gg 0$ and the RM value is small.

We have studied nine molecular electrides in this paper. Three of them are classified as oneelectron electrides $\left(1-P_{0}>0.5\right.$ and $\left.\operatorname{EOS}[1]=-1\right)$ : TCNQLi $2, \mathrm{Mg}_{2} \mathrm{EP}$, and $\mathrm{Mg}_{2} @ \mathrm{C}_{60}$. Other three show an intermediate situation between zero- and one-electron electrides $\left(P_{0} \approx 0.5\right), \mathrm{TCNQNa}_{2}$, $\mathrm{TCNENa}_{3}$, and $\mathrm{TCNENa}_{4}(\mathrm{II})$. Finally, the other three molecular electrides are classified as lowelectron-number electrides $\left(0.5 \gg 1-P_{0} \gg 0\right), \mathrm{Li} @$ calix[4]pyrrole, Na@calix[4]pyrrole, and $e @ \mathrm{C}_{60} \mathrm{~F}_{60}$. We believe this classification highlights the strength of the electride character and will prove useful in the design of new electrides.

\section{Acknowledgement}

The authors are indebted to Dr. Pedro Salvador for helpful discussions. This work has been supported by grants from the Spanish government MICINN (PGC2018-098212-B-C21, PGC2018098212-B-C22, CTQ2016-80375-P, and EUR2019-103825), Generalitat de Catalunya (2017SGR39), Diputación Foral de Gipuzkoa (2019-CIEN-000092-01) and Gobierno Vasco-Eusko Jaurlaritza (IT1254-19, PRE_2020_2_0015 and PIBA19-0004). E.R.C. acknowledges funding from the Juan 


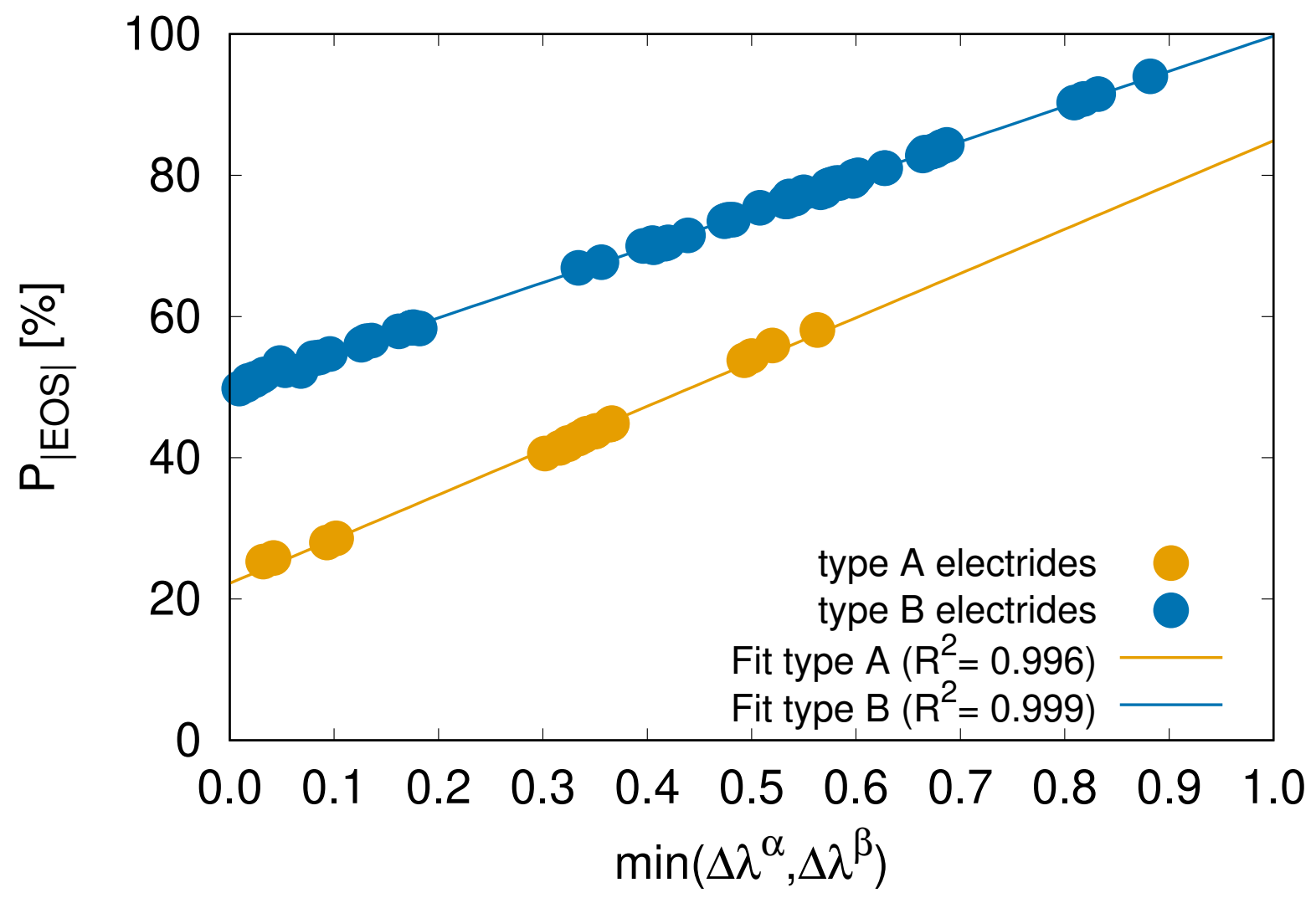

Figure 9: Correlation between the probability of finding in the NNA basin exactly the number of electrons predicted by the EOS analysis $\left(P_{|\mathrm{EOS}|}\right)$, and the smallest gap between the occupancies of the lowest occupied EAO $\left(\lambda_{\mathrm{LO}}\right)$ and first unoccupied EAO $\left(\lambda_{\mathrm{FU}}\right)$. Both the gap, $\Delta \lambda$, and EOS analysis were obtained with the type 1 fragmentation. The plot includes data for all methods and basis sets (excluding MP2) for which one NNA was found.

de la Cierva program IJCI-2017-34658. We are also grateful for the computational time from the Consorci de Serveis Universitaris de Catalunya (CSUC), DIPC and the SGI/IZO-SGIker UPV/EHU.

\section{Supporting Information Available}

NLOPs of $\mathrm{TCNENa}_{3}$ and $\mathrm{TCNENa}_{4}(\mathrm{II})$. Results obtained with the MN15 density functional approximation. Correlation plots between various descriptors of the NNA character. Geometries of all the molecules optimized at the CAM-B3LYP/ma-TZVP level of theory. 


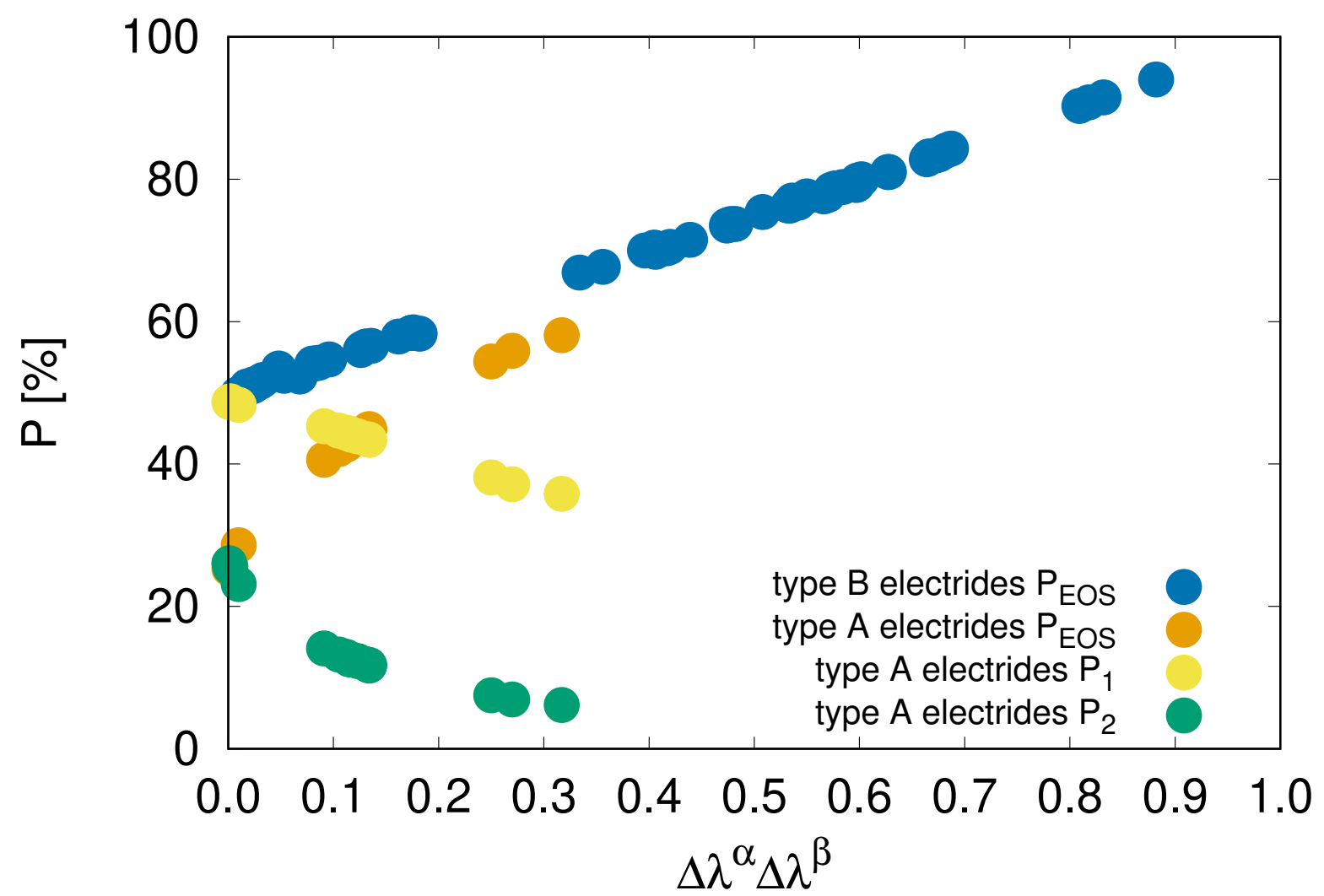

Figure 10: Correlation between the probability of finding exactly 0,1 , or 2 electrons in the NNA basin, and the product of the gap between the occupancies of the lowest occupied EAO ( $\left.\lambda_{\mathrm{LO}}\right)$ and first unoccupied EAO $\left(\lambda_{\mathrm{FU}}\right)$ for $\alpha$ and $\beta$ electrons. $P_{|\mathrm{EOS}|}$ is the probability of finding the number of electrons predicted by EOS. Both gap and IEOSI were obtained with the type 1 fragmentation. The plot includes data for all methods and basis sets (excluding MP2) for which one NNA was found.

\section{References}

(1) Dye, J. L. Electrons as anions. Science 2003, 301, 607-608.

(2) Dye, J. L. Electrides: ionic salts with electrons as the anions. Science 1990, 247, 663-668.

(3) Dye, J. L.; DeBacker, M. G. Physical and chemical properties of alkalides and electrides. Ann. Rev. Phys. Chem. 1987, 38, 271-299.

(4) Dye, J. L. Electrides: early examples of quantum confinement. Acc. Chem. Res. 2009, 42, $1564-1572$. 
(5) Dye, J. L.; Ceraso, J. M.; Lok, M.; Barnett, B.; Tehan, F. J. Crystalline salt of the sodium anion $\left(\mathrm{Na}^{-}\right)$. J. Am. Chem. Soc. 1974, 96, 608-609.

(6) Ellaboudy, A.; Dye, J. L.; Smith, P. B. Cesium 18-crown-6 compounds. A crystalline ceside and a crystalline electride. J. Am. Chem. Soc. 1983, 105, 6490-6491.

(7) Dawes, S. B.; Ward, D. L.; Huang, R. H.; Dye, J. L. First electride crystal structure. J. Am. Chem. Soc. 1986, 108, 3534-3535.

(8) Dye, J. L. Anionic electrons in electrides. Nature 1993, 365, 10-11.

(9) Dye, J. L. Electrides: From 1D Heiseing CHains to 2D Pseudo-Metals. Inorg. Chem. 1997, $36,3816-3826$.

(10) Redko, M. Y.; Jackson, J. E.; Huang, R. H.; Dye, J. L. Design and synthesis of a thermally stable organic electride. J. Am. Chem. Soc. 2005, 127, 12416-12422.

(11) Matsuishi, S.; Toda, Y.; Miyakawa, M.; Hayashi, K.; Kamiya, T.; Hirano, M.; Tanaka, I.; Hosono, H. High-density electron anions in a nanoporous single crystal: $\left[\mathrm{Ca}_{24} \mathrm{Al}_{28} \mathrm{O}_{64}\right]^{4+}\left(4 \mathrm{e}^{-}\right)$. Science 2003, 301, 626-629.

(12) Toda, Y.; Yanagi, H.; Ikenaga, E.; Kim, J. J.; Kobata, M.; Ueda, S.; Kamiya, T.; Hirano, M.; Kobayashi, K.; Hosono, H. Work Function of a Room-Temperature, Stable Electride $\left[\mathrm{Ca}_{24} \mathrm{Al}_{28} \mathrm{O}_{64}\right]^{4+}\left(4 \mathrm{e}^{-}\right)$. Adv. Mat. 2007, 19, 3564-3569.

(13) Yanagi, H.; Kuroda, T.; Kim, K.-B.; Toda, Y.; Kamiya, T.; Hosono, H. Electron injection barriers between air-stable electride with low work function, $\mathrm{C}_{12} \mathrm{~A}_{7}: \mathrm{e}^{-}$, and pentacene, $\mathrm{C}_{60}$ and copper phthalocyanine. J. Mater. Chem. 2012, 22, 4278-4281.

(14) Buchammagari, H.; Toda, Y.; Hirano, M.; Hosono, H.; Takeuchi, D.; Osakada, K. Room temperature-stable electride as a synthetic organic reagent: application to pinacol coupling reaction in aqueous media. Org. Lett. 2007, 9, 4287-4289. 
(15) Yanagi, H.; Kim, K.-B.; Koizumi, I.; Kikuchi, M.; Hiramatsu, H.; Miyakawa, M.; Kamiya, T.; Hirano, M.; Hosono, H. Low threshold voltage and carrier injection properties of inverted organic light-emitting diodes with $\left[\mathrm{Ca}_{24} \mathrm{Al}_{28} \mathrm{O}_{64}\right]^{4+}\left(4 \mathrm{e}^{-}\right)$cathode and $\mathrm{Cu}_{2-x} \mathrm{Se}$ anode. J. Phys. Chem. C 2009, 113, 18379-18384.

(16) Hayashi, K. Heavy doping of $\mathrm{H}^{-}$ion in $12 \mathrm{CaO} \cdot 7 \mathrm{Al}_{2} \mathrm{O}_{3}$. J. Solid State Chem. 2011, 184, $1428-1432$.

(17) Kitano, M.; Inoue, Y.; Yamazaki, Y.; Hayashi, F.; Kanbara, S.; Matsuishi, S.; Yokoyama, T.; Kim, S.-W.; Hara, M.; Hosono, H. Ammonia synthesis using a stable electride as an electron donor and reversible hydrogen store. Nat. Chem. 2012, 4, 934-940.

(18) Li, J.; Yin, B.; Fuchigami, T.; Inagi, S.; Hosono, H.; Ito, S. Application of $12 \mathrm{CaO} \cdot 7 \mathrm{Al}_{2} \mathrm{O}_{3}$ electride as a new electrode for superoxide ion generation and hydroxylation of an arylboronic acid. Electrochem. Commun. 2012, 17, 52-55.

(19) Kamiya, T.; Aiba, S.; Miyakawa, M.; Nomura, K.; Matsuishi, S.; Hayashi, K.; Ueda, K.; Hirano, M.; Hosono, H. Field-Induced Current Modulation in Nanoporous Semiconductor, Electron-Doped $12 \mathrm{CaO} \cdot 7 \mathrm{Al}_{2} \mathrm{O}_{3}$. Chem. Mat. 2005, 17, 6311-6316.

(20) Watanabe, S.; Watanabe, T.; Ito, K.; Miyakawa, N.; Ito, S.; Hosono, H.; Mikoshiba, S. Secondary electron emission and glow discharge properties of $12 \mathrm{CaO} \cdot 7 \mathrm{Al}_{2} \mathrm{O}_{3}$ electride for fluorescent lamp applications. Sci. Technol. Adv. Mater. 2011, 12, 034410.

(21) Kim, S. W.; Shimoyama, T.; Hosono, H. Solvated Electrons in High-Temperature Melts and Glasses of the Room-Temperature Stable Electride $\left[\mathrm{Ca}_{24} \mathrm{Al}_{28} \mathrm{O}_{64}\right]^{4+} \cdot 4 \mathrm{e}^{-}$. Science 2011, $333,71-74$.

(22) Mizoguchi, H.; Okunaka, M.; Kitano, M.; Matsuishi, S.; Yokoyama, T.; Hosono, H. Hydride-Based Electride Material, $\mathrm{LnH}_{2}(\mathrm{Ln}=\mathrm{La}, \mathrm{Ce}$, or Y). Inorg. Chem. 2016, 55, 88338838. 
(23) Chanhom, P.; Fritz, K. E.; Burton, L. A.; Kloppenburg, J.; Filinchuk, Y.; Senyshyn, A.; Wang, M.; Feng, Z.; Insin, N.; Suntivich, J.; Hautier, G. $\mathrm{Sr}_{3} \mathrm{CrN}_{3}$ : A New Electride with a Partially Filled d-Shell Transition Metal. J. Am. Chem. Soc. 2019, 141, 10595-10598.

(24) Zhang, Y.; Wang, B.; Xiao, Z.; Lu, Y.; Kamiya, T.; Uwatoko, Y.; Kageyama, H.; Hosono, H. Electride and superconductivity behaviors in $\mathrm{Mn}_{5} \mathrm{Si}_{3}$-type intermetallics. Npj Quantum Mater. 2017, 2, 45.

(25) Wang, J.; Hanzawa, K.; Hiramatsu, H.; Kim, J.; Umezawa, N.; Iwanaka, K.; Tada, T.; Hosono, H. Exploration of Stable Strontium Phosphide-Based Electrides: Theoretical Structure Prediction and Experimental Validation. J. Am. Chem. Soc. 2017, 139, 15668-15680.

(26) Zhang, Y.; Xiao, Z.; Kamiya, T.; Hosono, H. Electron Confinement in Channel Spaces for One-Dimensional Electride. J. Phys. Chem. Lett. 2015, 6, 4966-4971.

(27) Lee, K.; Kim, S. W.; Toda, Y.; Matsuishi, S.; Hosono, H. Dicalcium nitride as a twodimensional electride with an anionic electron layer. Nature 2013, 494, 336-340.

(28) Lee, S. Y.; Hwang, J.-Y.; Park, J.; Nandadasa, C. N.; Kim, Y.; Bang, J.; Lee, K.; Lee, K. H.; Zhang, Y.; Ma, Y.; Hosono, H.; Lee, Y. H.; Kim, S.-G.; Kim, S. W. Ferromagnetic quasiatomic electrons in two-dimensional electride. Nat. Commun. 2020, 11, 1526.

(29) Lu, Y.; Wang, J.; Li, J.; Wu, J.; Kanno, S.; Tada, T.; Hosono, H. Realization of Mottinsulating electrides in dimorphic $\mathrm{Yb}_{5} \mathrm{Sb}_{3}$. Phys. Rev. B 2018, 98, 125128.

(30) Lu, Y.; Tada, T.; Toda, Y.; Ueda, S.; Wu, J.; Li, J.; Horiba, K.; Kumigashira, H.; Zhang, Y.; Hosono, H. Interlayer states arising from anionic electrons in the honeycomb-lattice-based compounds AeAlSi (Ae= Ca, Sr, Ba). Phys. Rev. B 2017, 95, 125117.

(31) Yan, J.-Q.; Ochi, M.; Cao, H. B.; Saparov, B.; Cheng, J.-G.; Uwatoko, Y.; Arita, R.; Sales, B. C.; Mandrus, D. G. Magnetic order of $\mathrm{Nd}_{5} \mathrm{~Pb}_{3}$ single crystals. J. Phys.: Condens. Matter 2018, 30, 135801. 
(32) Kang, S. H.; Bang, J.; Chung, K.; Nandadasa, C. N.; Han, G.; Lee, S.; Lee, K. H.; Lee, K.; Ma, Y.; Oh, S. H.; Kim, S.-G.; Kim, Y.-M.; Kim, S. W. Water- and acid-stable self-passivated dihafnium sulfide electride and its persistent electrocatalytic reaction. Sci. Adv. 2020, 6.

(33) Druffel, D. L.; Kuntz, K. L.; Woomer, A. H.; Alcorn, F. M.; Hu, J.; Donley, C. L.; Warren, S. C. Experimental Demonstration of an Electride as a 2D Material. J. Am. Chem. Soc. 2016, 138, 16089-16094.

(34) Druffel, D. L.; Woomer, A. H.; Kuntz, K. L.; Pawlik, J. T.; Warren, S. C. Electrons on the surface of 2D materials: from layered electrides to 2D electrenes. J. Mater. Chem. C 2017, $5,11196-11213$.

(35) Wu, J.; Gong, Y.; Inoshita, T.; Fredrickson, D. C.; Wang, J.; Lu, Y.; Kitano, M.; Hosono, H. Tiered Electron Anions in Multiple Voids of LaScSi and Their Applications to Ammonia Synthesis. Adv. Mater. 2017, 29, 1700924.

(36) Ye, T.-N.; Lu, Y.; Li, J.; Nakao, T.; Yang, H.; Tada, T.; Kitano, M.; Hosono, H. CopperBased Intermetallic Electride Catalyst for Chemoselective Hydrogenation Reactions. J. Am. Chem. Soc. 2017, 139, 17089-17097.

(37) Wu, J.; Li, J.; Gong, Y.; Kitano, M.; Inoshita, T.; Hosono, H. Intermetallic Electride Catalyst as a Platform for Ammonia Synthesis. Angew. Chem. Int. Ed. 2019, 58, 825-829.

(38) Li, J.; Wu, J.; Wang, H.; Lu, Y.; Ye, T.; Sasase, M.; Wu, X.; Kitano, M.; Inoshita, T.; Hosono, H. Acid-durable electride with layered ruthenium for ammonia synthesis: boosting the activity via selective etching. Chem. Sci. 2019, 10, 5712-5718.

(39) Mizoguchi, H.; Park, S.-W.; Kishida, K.; Kitano, M.; Kim, J.; Sasase, M.; Honda, T.; Ikeda, K.; Otomo, T.; Hosono, H. Zeolitic Intermetallics: LnNiSi (Ln = La-Nd). J. Am. Chem. Soc. 2019, 141, 3376-3379. 
(40) Ye, T.-N.; Lu, Y.; Xiao, Z.; Li, J.; Nakao, T.; Abe, H.; Niwa, Y.; Kitano, M.; Tada, T.; Hosono, H. Palladium-bearing intermetallic electride as an efficient and stable catalyst for Suzuki cross-coupling reactions. Nat. Commun. 2019, 10, 5653.

(41) Hu, Q.; Tan, R.; Yao, W.; Cui, Y.; Li, J.; Song, W. Preparation and X-ray photoelectron spectroscopic characterization of Sn-doped $\mathrm{C}_{12} \mathrm{~A}_{7}: \mathrm{e}^{-}$electride nanoparticles. Appl. Surf. Sci. 2020, 508, 145244.

(42) Lu, Y.; Li, J.; Ye, T.-N.; Kobayashi, Y.; Sasase, M.; Kitano, M.; Hosono, H. Synthesis of Rare-Earth-Based Metallic Electride Nanoparticles and Their Catalytic Applications to Selective Hydrogenation and Ammonia Synthesis. ACS Catal. 2018, 8, 11054-11058.

(43) He, H.-M.; Li, Y.; Yang, H.; Yu, D.; Li, S.-Y.; Wu, D.; Hou, J.-H.; Zhong, R.-L.; Zhou, Z.J.; Gu, F.-L., et al. Efficient external electric field manipulated nonlinear optical switches of all-metal electride molecules with infrared transparency: nonbonding electron transfer forms an excess electron lone pair. J. Phys. Chem. C 2017, 121, 958-968.

(44) He, H.-M.; Luis, J. M.; Chen, W.-H.; Yu, D.; Li, Y.; Wu, D.; Sun, W.-M.; Li, Z.-R. Nonlinear optical response of endohedral all-metal electride cages $2 \mathrm{e}^{-} \mathrm{Mg}^{2+}\left(\mathrm{M} @ \mathrm{E}_{12}\right)^{2-} \mathrm{Ca}^{2+}(\mathrm{M}=$ Ni, Pd, and Pt; E= Ge, Sn, and Pb). J. Mater. Chem. C 2019, 7, 645-653.

(45) Postils, V.; Garcia-Borrás, M.; Solà, M.; Luis, J. M.; Matito, E. On the existence and characterization of molecular electrides. Chem. Commun. 2015, 51, 4865-4868.

(46) El Bakouri, O.; Postils, V.; Garcia-Borràs, M.; Duran, M.; Luis, J. M.; Calvello, S.; Soncini, A.; Matito, E.; Feixas, F.; Solà, M. Metal Cluster Electrides: A New Type of Molecular Electride with Delocalised Polyattractor Character. Chem. Eur. J. 2018, 24, 9853-9859.

(47) Marqués, M.; Ackland, G. J.; Lundegaard, L. F.; Stinton, G.; Nelmes, R. J.; McMahon, M. I.; Contreras-García, J. Potassium under pressure: A pseudobinary ionic compound. Phys. Rev. Lett. 2009, 103, 115501. 
(48) Marqués, M.; McMahon, M.; Gregoryanz, E.; Hanfland, M.; Guillaume, C.; Pickard, C.; Ackland, G.; Nelmes, R. Crystal structures of dense lithium: a metal-semiconductor-metal transition. Phys. Rev. Lett. 2011, 106, 095502.

(49) Gatti, M.; Tokatly, I. V.; Rubio, A. Sodium: a charge-transfer insulator at high pressures. Phys. Rev. Lett. 2010, 104, 216404.

(50) Li, P.; Gao, G.; Wang, Y.; Ma, Y. Crystal structures and exotic behavior of magnesium under pressure. J. Phys. Chem. C 2010, 114, 21745-21749.

(51) Becke, A. D.; Edgecombe, K. E. A simple mesure of electron localization in atomic and molecular systems. J. Chem. Phys. 1990, 92, 5397-5403.

(52) Miao, M.-S.; Hoffmann, R. High Pressure Electrides: The Chemical Nature of Interstitial Quasiatoms. J. Am. Chem. Soc. 2015, 137, 3631-3637.

(53) Miao, M.-S.; Hoffmann, R. High Pressure Electrides: A Predictive Chemical and Physical Theory. Acc. Chem. Res. 2014, 47, 1311-1317.

(54) Ward, D. L.; Huang, R. H.; Dye, J. L. Structures of alkalides and electrides. I. Structure of potassium cryptand[2.2.2] electride. Acta Cryst. C 1988, 44, 1374-1376.

(55) Huang, R. H.; Faber, M. K.; Moeggenborg, K. J.; Ward, D. L.; Dye, J. L. Structure of $\mathrm{K}^{+}$(cryptand[2.2.2]) electride and evidence for trapped electron pairs. Nature 1988, 331, 599-601.

(56) Dawes, S. B.; Eglin, J. L.; Moeggenborg, K. J.; Kim, J.; Dye, J. L. Cs ${ }^{+}\left(15-\right.$ crown-5) $_{2} \cdot e^{-}$. A crystalline antiferromagnetic electride. J. Am. Chem. Soc. 1991, 113, 1605-1609.

(57) Wagner, M. J.; Huang, R. H.; Eglin, J. L.; Dye, J. L. An electride with a large six-electron ring. Nature 1994, 368, 726-729.

(58) Huang, R. H.; Wagner, M. J.; Gilbert, D. J.; Reidy-Cedergren, K. A.; Ward, D. L.; Faber, M. K.; Dye, J. L. Structure and Properties of $\mathrm{Li}^{+}\left(\right.$Cryptand [2.1.1])e ${ }^{-}$, an Electride 
with a 1D "Spin-Ladder-like" Cavity-Channel Geometry. J. Am. Chem. Soc. 1997, 119, $3765-3772$.

(59) Xie, Q.; Huang, R. H.; Ichimura, A. S.; Phillips, R. C.; Pratt, W. P.; Dye, J. L. Structure and Properties of a New Electride, $\mathrm{Rb}^{+}\left(\right.$cryptand[2.2.2]) $\mathrm{e}^{-}$. J. Am. Chem. Soc. 2000, 122, 6971-6978.

(60) Zhang, X.; Xiao, Z.; Lei, H.; Toda, Y.; Matsuishi, S.; Kamiya, T.; Ueda, S.; Hosono, H. Two-Dimensional Transition-Metal Electride $\mathrm{Y}_{2}$ C. Chem. Mater. 2014, 26, 6638-6643.

(61) Lu, Y.; Li, J.; Tada, T.; Toda, Y.; Ueda, S.; Yokoyama, T.; Kitano, M.; Hosono, H. Water Durable Electride $\mathrm{Y}_{5} \mathrm{Si}_{3}$ : Electronic Structure and Catalytic Activity for Ammonia Synthesis. J. Am. Chem. Soc. 2016, 138, 3970-3973.

(62) Hara, M.; Kitano, M.; Hosono, H. Ru-Loaded $\mathrm{C}_{12} \mathrm{~A}_{7}: \mathrm{e}^{-}$Electride as a Catalyst for Ammonia Synthesis. ACS Catal. 2017, 7, 2313-2324.

(63) Faseela, K. P.; Kim, Y. J.; Kim, S.-G.; Kim, S. W.; Baik, S. Dramatically Enhanced Stability of Silver Passivated Dicalcium Nitride Electride: Ag-Ca 2 N. Chem. Mater. 2018, 30, 78037812.

(64) Xiao, Y.; Zhang, X.; Li, R.; Zhang, J. Rapid Synthesis and Electric Transport Properties of $\left(\mathrm{Ca}_{1-x} \mathrm{Ba}_{x}\right) 12 \mathrm{Al}_{14} \mathrm{O}_{33}$ Electrides. J. Electron. Mater. 2020, 49, 2471-2478.

(65) Zhang, X.; Feng, Q.; Zhao, J.; Liu, H.; Li, J.; Xiao, Y.; Li, F.; Lu, Q. Sr-doping enhanced electrical transport and thermionic emission of single crystal $12 \mathrm{CaO} \cdot 7 \mathrm{Al}_{2} \mathrm{O}_{3}$ electride. Curr. Appl. Phys. 2020, 20, $96-101$.

(66) Dale, S. G.; Johnson, E. R. Theoretical Descriptors of Electrides. J. Phys. Chem. A 2018, $122,9371-9391$.

(67) Miyakawa, M.; Kim, S. W.; Hirano, M.; Kohama, Y.; Kawaji, H.; Atake, T.; Ikegami, H.; 
Kono, K.; Hosono, H. Superconductivity in an Inorganic Electride $12 \mathrm{CaO} \cdot 7 \mathrm{Al}_{2} \mathrm{O}_{3}: \mathrm{e}^{-} . J$. Am. Chem. Soc. 2007, 129, 7270-7271.

(68) He, Y. The structural, electronic, elastic and thermodynamics properties of 2D transitionmetal electride Y2C via first-principles calculations. J. Alloys Compd. 2016, 654, 180-184.

(69) Ge, Y.; Guan, S.; Liu, Y. Two dimensional superconductors in electrides. New J. Phys. 2017, 19, 123020.

(70) Chen, W.; Li, Z.-R.; Wu, D.; Li, Y.; Sun, C.-C.; Gu, F. L. The structure and the large nonlinear optical properties of Li@Calix[4] pyrrole. J. Am. Chem. Soc. 2005, 127, 1097710981.

(71) Garcia-Borràs, M.; Solà, M.; Luis, J. M.; Kirtman, B. Electronic and vibrational nonlinear optical properties of five representative electrides. J. Chem. Theory Comput. 2012, 8, 26882697.

(72) Singh, D. J.; Krakauer, H.; Haas, C.; Pickett, W. E. Theoretical determination that electrons act as anions in the electride $\mathrm{Cs}^{+}(15-\text { crown-5) })_{2} \mathrm{e}^{-}$. Nature 1993, 365, 39-42.

(73) Toda, Y.; Kubota, Y.; Hirano, M.; Hirayama, H.; Hosono, H. Surface of Room-TemperatureStable Electride $\left[\mathrm{Ca}_{24} \mathrm{Al}_{28} \mathrm{O}_{64}\right]^{4+}\left(4 \mathrm{e}^{-}\right)$: Preparation and Its Characterization by AtomicResolution Scanning Tunneling Microscopy. ACS nano 2011, 5, 1907-1914.

(74) Silvi, B.; Savin, A. Classification of chemical bonds based on topological analysis of electron localization function. Nature 1994, 371, 683-686.

(75) Matito, E.; Silvi, B.; Duran, M.; Solà, M. Electron localization function at the correlated level. J. Chem. Phys. 2006, 125, 024301.

(76) Johnson, E. R.; Keinan, S.; Mori-Sánchez, P.; Contreras-García, J.; Cohen, A. J.; Yang, W. Revealing noncovalent interactions. J. Am. Chem. Soc. 2010, 132, 6498-6506. 
(77) Contreras-García, J.; Johnson, E. R.; Keinan, S.; Chaudret, R.; Piquemal, J.-P.; Beratan, D. N.; Yang, W. NCIPLOT: a program for plotting noncovalent interaction regions. $J$. Chem. Theory Comput. 2011, 7, 625-632.

(78) Schmider, H. L.; Becke, A. D. Chemical content of the kinetic energy density. J. Mol. Struct. (Theochem) 2000, 527, 51-61.

(79) Bader, R. F. W. Atoms in Molecules: A Quantum Theory; Oxford University Press: Oxford, 1990.

(80) Dale, S. G.; Otero-de-la Roza, A.; Johnson, E. R. Density-functional description of electrides. Phys. Chem. Chem. Phys. 2014, 16, 14584-14593.

(81) Burke, K.; Perdew, J. P.; Levy, M. Improving energies by using exact electron densities. Phys. Rev. A 1996, 53, R2915.

(82) Sancho-García, J.; Pérez-Jiménez, A. Improved accuracy with medium cost computational methods for the evaluation of bond length alternation of increasingly long oligoacetylenes. Phys. Chem. Chem. Phys. 2007, 9, 5874-5879.

(83) Casademont-Reig, I.; Woller, T.; Contreras-García, J.; Alonso, M.; Torrent-Sucarrat, M.; Matito, E. New electron delocalization tools to describe the aromaticity in porphyrinoids. Phys. Chem. Chem. Phys. 2018, 20, 2787-2796.

(84) Casademont-Reig, I.; Ramos-Cordoba, E.; Torrent-Sucarrat, M.; Matito, E. How do the Hückel and Baird Rules Fade away in Annulenes? Molecules 2020, 25, 711.

(85) Casademont-Reig, I.; Ramos-Cordoba, E.; Torrent-Sucarrat, M.; Matito, E. Aromaticity descriptors based on electron delocalization. Book chapter, submitted

(86) Torrent-Sucarrat, M.; Navarro, S.; Cossío, F. P.; Anglada, J. M.; Luis, J. M. Relevance of the DFT method to study expanded porphyrins with different topologies. J. Comput. Chem. 2017, 38, 2819-2828. 
(87) Chen, W.; Li, Z.-R.; Wu, D.; Li, Y.; Sun, C.-C.; Gu, F. L.; Aoki, Y. Nonlinear optical properties of alkalides $\mathrm{Li}^{+}\left(\right.$calix[4] pyrrole) $\mathrm{M}^{-}(\mathrm{M}=\mathrm{Li}, \mathrm{Na}$, and $\mathrm{K})$ : Alkali anion atomic number dependence. J. Am. Chem. Soc. 2006, 128, 1072-1073.

(88) Das, P.; Saha, R.; Chattaraj, P. K. Encapsulation of $\mathrm{Mg}_{2}$ inside a $\mathrm{C}_{60}$ cage forms an electride. J. Comput. Chem. 2020, 41, 1645-1653.

(89) Li, Z.-J.; Wang, F.-F.; Li, Z.-R.; Xu, H.-L.; Huang, X.-R.; Wu, D.; Chen, W.; Yu, G.-T.; Gu, F. L.; Aoki, Y. Large static first and second hyperpolarizabilities dominated by excess electron transition for radical ion pair salts $\mathrm{M}_{2}^{+} \mathrm{TCNQ}^{-}(\mathrm{M}=\mathrm{Li}, \mathrm{Na}, \mathrm{K})$. Phys. Chem. Chem. Phys. 2009, 11, 402-408.

(90) Salehi, N.; Vessally, E.; Edjlali, L.; Alkorta, I.; Es' haghi, M. he investigation of cavitytrapped electrons in the $\mathrm{Na}_{n} @$ Tetracyanoethylene $(\mathrm{n}=1-4)$ systems. Chem. Rev. Lett. 2020, $3,207-212$.

(91) Saha, R.; Chattaraj, P. K. Activation of Small Molecules $\left(\mathrm{H}_{2}, \mathrm{CO}_{2}, \mathrm{~N}_{2} \mathrm{O}, \mathrm{CH}_{4}\right.$, and $\left.\mathrm{C}_{6} \mathrm{H}_{6}\right)$ by a Porphyrinoid-Based Dimagnesium (I) Complex, an Electride. ACS omega 2018, 3, 17199-17211.

(92) Wang, Y.-F.; Li, Z.-R.; Wu, D.; Sun, C.-C.; Gu, F.-L. Excess electron is trapped in a large single molecular cage $\mathrm{C}_{60} \mathrm{~F}_{60}$. J. Comput. Chem. 2010, 31, 195-203.

(93) Yanai, T.; Tew, D. P.; Handy, N. C. A new hybrid exchange-correlation functional using the Coulomb-attenuating method (CAM-B3LYP). Chem. Phys. Lett. 2004, 393, 51-57.

(94) Zheng, J.; Xu, X.; Truhlar, D. G. Minimally augmented Karlsruhe basis sets. Theor. Chim. Acta (Berlin) 2011, 128, 295-305.

(95) Casademont-Reig, I.; Ramos-Cordoba, E.; Torrent-Sucarrat, M.; Matito, E. How aromatic ara molecular nanorings? The case of a six-porphyrin nanoring. submitted 
(96) Becke, A. D. Density-functional thermochemistry. III. The role of exact exchange. J. Chem. Phys. 1993, 98, 5648-5652.

(97) Stephens, P. J.; Devlin, F. J.; Chabalowski, C. F.; Frisch, M. J. Ab initio calculation of vibrational absorption and circular dichroism spectra using density functional force fields. J. Phys. Chem. 1994, 98, 11623-11627.

(98) Zhao, Y.; Truhlar, D. G. The M06 suite of density functionals for main group thermochemistry, thermochemical kinetics, noncovalent interactions, excited states, and transition elements: two new functionals and systematic testing of four M06-class functionals and 12 other functionals. Theor. Chem. Acc. 2008, 120, 215-241.

(99) Haoyu, S. Y.; He, X.; Li, S. L.; Truhlar, D. G. MN15: A Kohn-Sham global-hybrid exchange-correlation density functional with broad accuracy for multi-reference and singlereference systems and noncovalent interactions. Chem. Sci. 2016, 7, 5032-5051.

(100) Møller, C.; Plesset, M. S. Note on an approximation treatment for many-electron systems. Phys. Rev. 1934, 46, 618.

(101) Lee, T. J.; Taylor, P. R. A Diagnostic for Determining the Quality of Single-Reference Electron Correlation Methods. Int. J. Quantum Chem. 1989, 23, 199-207.

(102) Lee, T. J. Comparison of the T1 and D1 diagnostics for electronic structure theory: a new definition for the open-shell D1 diagnostic. Chem. Phys. Lett. 2003, 372, 362-367.

(103) Ramos-Cordoba, E.; Salvador, P.; Matito, E. Separation of dynamic and nondynamic correlation. Phys. Chem. Chem. Phys. 2016, 18, 24015-24023.

(104) Ramos-Cordoba, E.; Matito, E. Local Descriptors of dynamic and nondynamic correlation. J. Chem. Theory Comput. 2017, 13, 2705-2711.

(105) Via-Nadal, M.; Rodríguez-Mayorga, M.; Ramos-Cordoba, E.; Matito, E. Singling out Weak and Strong Correlation. J. Phys. Chem. Lett. 2019, 10. 
(106) Via-Nadal, M.; Rodríguez-Mayorga, M.; Ramos-Cordoba, E.; Matito, E. Range Separation of the Coulomb Hole. submitted,

(107) Löwdin, P.-O. Quantum theory of many-particle systems. I. Physical interpretations by means of density matrices, natural spin-orbitals, and convergence problems in the method of configurational interaction. Phys. Rev. 1955, 97, 1474-1489.

(108) Smith Jr, V. H. Approximate natural orbitals for carbon 1 S. Theor. Chim. Acta (Berlin) 1967, 7, 245.

(109) Frisch, M. J. et al. Gaussian 16 Revision C.01. 2016; Gaussian Inc. Wallingford CT.

(110) Stanton, J. F.; Gauss, J.; Cheng, L.; Harding, M. E.; Matthews, D. A.; Szalay, P. G. CFOUR, Coupled-Cluster techniques for Computational Chemistry, a quantum-chemical program package. With contributions from A.A. Auer, R.J. Bartlett, U. Benedikt, C. Berger, D.E. Bernholdt, S. Blaschke, Y. J. Bomble, S. Burger, O. Christiansen, D. Datta, F. Engel, R. Faber, J. Greiner, M. Heckert, O. Heun, M. Hilgenberg, C. Huber, T.-C. Jagau, D. Jonsson, J. Jusélius, T. Kirsch, K. Klein, G.M. KopperW.J. Lauderdale, F. Lipparini, T. Metzroth, L.A. Mück, D.P. O’Neill, T. Nottoli, D.R. Price, E. Prochnow, C. Puzzarini, K. Ruud, F. Schiffmann, W. Schwalbach, C. Simmons, S. Stopkowicz, A. Tajti, J. Vázquez, F. Wang, J.D. Watts and the integral packages MOLECULE (J. Almlöf and P.R. Taylor), PROPS (P.R. Taylor), ABACUS (T. Helgaker, H.J. Aa. Jensen, P. Jørgensen, and J. Olsen), and ECP routines by A. V. Mitin and C. van Wüllen. For the current version, see http://www.cfour.de.

(111) Keith, T. A. AIMAll (Version 14.11.23). 2014; TK Gristmill Software, Overland Park KS, USA (aim.tkgristmill.com).

(112) Pendás, A. M.; Blanco, M. A.; Costales, A.; Sánchez, P. M.; Luaña, V. Non-nuclear maxima of the electron density. Phys. Rev. Lett. 1999, 83, 1930-1933.

(113) Fradera, X.; Austen, M. A.; Bader, R. F. W. The Lewis Model and Beyond. J. Phys. Chem. A 1999, 103, 304-314. 
(114) Matito, E.; Solà, M.; Salvador, P.; Duran, M. Electron sharing indexes at the correlated level. Application to aromaticity calculations. Faraday Discuss. 2007, 135, 325-345.

(115) Ramos-Cordoba, E.; Postils, V.; Salvador, P. Oxidation states from wave function analysis. J. Chem. Theory Comput. 2015, 11, 1501-1508.

(116) Postils, V.; Delgado-Alonso, C.; Luis, J. M.; Salvador, P. An Objective Alternative to IUPAC's Approach To Assign Oxidation States. Angew. Chem. Int. Ed. 2018, 130, 1068510689.

(117) Min, X.; Popov, I. A.; Pan, F.-X.; Li, L.-J.; Matito, E.; Sun, Z.-M.; Wang, L.-S.; Boldyrev, A. I. All-Metal Antiaromaticity in $\mathrm{Sb}_{4}$-Type Lanthanocene Anions. Angew. Chem. Int. Ed. 2016, 55, 5531-5535.

(118) Grande-Aztatzi, R.; Mercero, J. M.; Matito, E.; Frenking, G.; Ugalde, J. M. The aromaticity of dicupra [10]annulenes. Phys. Chem. Chem. Phys. 2017, 19, 9669-9675.

(119) Postils, V.; Rodríguez, M.; Sabenya, G.; Conde, A.; Díaz-Requejo, M. M.; Pérez, P. J.; Costas, M.; Solà, M.; Luis, J. M. Mechanism of the Selective Fe-Catalyzed Arene CarbonHydrogen Bond Functionalization. ACS Catal. 2018, 8, 4313-4322.

(120) Gimferrer, M.; Van der Mynsbrugge, J.; Bell, A. T.; Salvador, P.; Head-Gordon, M. Facing the challenges of borderline oxidation state assignments using state-of-the-art computational methods. Inorg. Chem. 2020, 59, 15410-15420.

(121) Ampßler, T.; Monsch, G.; Popp, J.; Riggenmann, T.; Salvador, P.; Schröder, D.; Klüfers, P. Not Guilty on Every Count: The "Non-Innocent" Nitrosyl Ligand in the Framework of IUPAC's Oxidation-State Formalism. Angew. Chem. Int. Ed. 2020, 59, 12381-12386.

(122) Salvador, P.; Ramos-Cordoba, E. APOST-3D program. 2012; Universitat de Girona (Spain).

(123) Martín Pendás, A.; Francisco, E.; Blanco, M. A. An electron number distribution view of chemical bonds in real space. Phys. Chem. Chem. Phys. 2007, 9, 1087-1092. 
(124) Cancés, E.; Keriven, R.; Lodier, F.; Savin, A. How electrons guard the space: shape optimization with probability distribution criteria. Theor. Chem. Acc. 2004, 111, 373-380.

(125) Bader, R. F. W.; Stephens, M. E. Fluctuation and correlation of electrons in molecular systems. Chem. Phys. Lett. 1974, 26, 445-449.

(126) Bader, R. F. W.; Stephens, M. E. Spatial localization of the electronic pair and number distributions in molecules . J. Am. Chem. Soc. 1975, 97, 7391-7399.

(127) Chalvet, O.; Daudel, R.; Diner, S.; Malrieu, J. P. Localization and Delocalization in quantum Chemistry; Reidel: Dordrecht, The Netherlands, 1975; Vol. I.

(128) Chalvet, O.; Daudel, R.; Diner, S.; Malrieu, J. P. Localization and Delocalization in quantum Chemistry; Reidel: Dordrecht, The Netherlands, 1976; Vol. II.

(129) Francisco, E.; Martín Pendás, A.; Blanco, M. A. Electron number probability distributions for correlated wave functions. J. Chem. Phys. 2007, 126, 094102.

(130) Francisco, E.; Martín Pendás, A.; Blanco, M. A. EDF: Computing electron number probability distribution functions in real space from molecular wave functions. Comput. Phys. Commun. 2008, 178, 621-634.

(131) Martín Pendás, A.; Francisco, E. Chemical bonding from the statistics of the electron distribution. Chem. Phys. Chem. 2019, 20, 2722-2741.

(132) Pendás, Á. M.; Francisco, E. Local spin and open quantum systems: clarifying misconceptions, unifying approaches. Phys. Chem. Chem. Phys. accepted,

(133) Ramos-Cordoba, E.; Matito, E.; Mayer, I.; Salvador, P. Toward a Unique Definition of the Local Spin. J. Chem. Theory Comput. 2012, 8, 1270-1279.

(134) Ramos-Cordoba, E.; Matito, E.; Salvador, P.; Mayer, I. Local spins: improved Hilbert-space analysis. Phys. Chem. Chem. Phys. 2012, 14, 15291-15298. 


\section{Graphical TOC Entry}

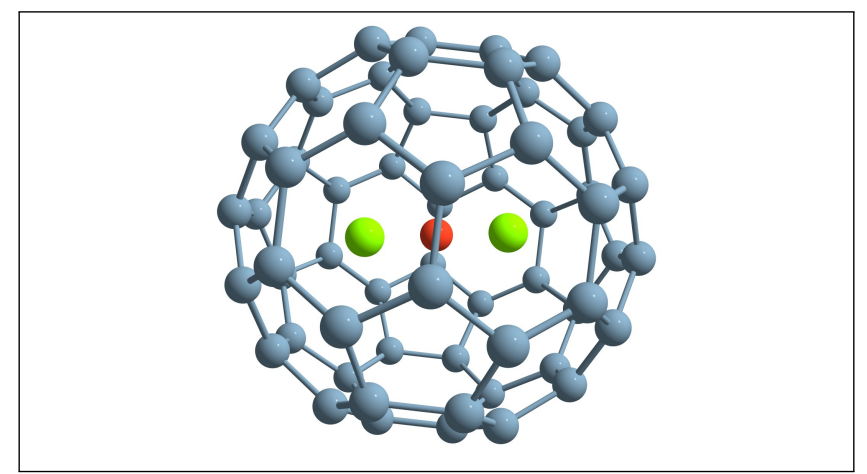

